\title{
Lineage-specific control of convergent differentiation by a Forkhead repressor
}

Karolina Mizeracka ${ }^{1,2}$, Julia M. Rogers ${ }^{3,4}$, Jonathan D. Rumley ${ }^{5}$, Shai Shaham ${ }^{6}$, Martha L. Bulyk ${ }^{3,4,7}$, John I. Murray ${ }^{5}$, and Maxwell G. Heiman ${ }^{1,2, *}$

${ }^{1}$ Department of Genetics, Blavatnik Institute, Harvard Medical School, Boston, MA

${ }^{2}$ Division of Genetics and Genomics, Boston Children's Hospital, Boston, MA

${ }^{3}$ Division of Genetics, Department of Medicine, Brigham and Women's Hospital and Harvard Medical School, Boston, MA

${ }^{4}$ Committee on Higher Degrees in Biophysics, Harvard University, Cambridge, MA

${ }^{5}$ Department of Genetics, Perelman School of Medicine, University of Pennsylvania, Philadelphia, PA

${ }^{6}$ The Rockefeller University, New York, NY

${ }^{7}$ Department of Pathology, Brigham and Women's Hospital and Harvard Medical School, Boston, MA

*heiman@genetics.med.harvard.edu 


\begin{abstract}
During convergent differentiation, multiple developmental lineages produce a highly similar or identical cell type. However, the molecular players that drive convergent differentiation are not known. Here, we show that the C. elegans Forkhead transcription factor UNC-130 is required in only one of three convergent lineages that produce the same glial cell type. UNC-130 acts transiently as a repressor in progenitors and newlyborn terminal cells to allow the proper specification of cells related by lineage rather than by cell type. Specification defects correlate with UNC-130:DNA binding, and UNC-130 can be functionally replaced by its human homolog, the neural crest lineage determinant FoxD3. We propose that, in contrast to terminal selectors that activate cell-type specific transcriptional programs in terminally differentiating cells, UNC-130 acts earlier to enable molecularly distinct progenitors to produce equivalent cell types. These findings provide evidence that convergent differentiation involves distinct transcriptional paths leading to the same cell type.
\end{abstract}




\section{INTRODUCTION}

Development is the story of how a single cell divides to give rise to lineages that produce every cell type in the body. The standard framework for understanding this process is that cell lineages branch to produce increasingly divergent cell states, with each cell type produced exclusively by a single branch (Fig. 1A). An exception to this paradigm is convergent differentiation, a phenomenon in which multiple lineages produce identical or highly similar cell types (Fig. 1B). For example, mesoderm and neural crest lineages both produce the same type of heart cell (Dupin et al., 2018; Keyte \& Hutson, 2012), and embryonic and extra-embryonic lineages both produce gut endoderm (Kwon et al., 2008). With the advent of single-cell RNA profiling coupled to lineage tracing, it is now appreciated that convergent differentiation is surprisingly prevalent in vertebrates (Chan et al., 2019; Liu et al., 2019; McKenna \& Gagnon, 2019; Wagner et al., 2018). However, the molecular players that drive convergent differentiation remain unclear.

Importantly, in C. elegans, convergent differentiation has been appreciated for decades, ever since the complete developmental lineage was mapped (Sulston et al., 1983). A number of cell types that are present in symmetric anatomical regions - such as the dorsal and ventral equivalents of a given cell type - are produced through convergent differentiation by multipotent sublineages, which we will refer to as convergent lineages. A key question to understanding convergent differentiation is to determine if progenitors always follow the same path to produce a given cell type - that is, are shared or lineagespecific transcriptional trajectories employed across lineages that produce the same cell type? Intriguingly, several C. elegans mutants affect only a subset of convergently- 
derived cells: for example $m l s-2$ mutations affect ventral, but not dorsal CEP sheath glia; lin-32 mutations affect dorsal, but not ventral CEP neurons; and ceh-10 mutations affect dorsal, but not lateral or ventral RME neurons (Doitsidou et al., 2010; Forrester et al., 1998; Rojo Romanos et al., 2017; Yoshimura et al., 2008). These findings suggest that convergent lineages use distinct transcriptional trajectories to specify the same cell type. However, the mechanism by which lineage-specific transcription factors mediate convergent differentiation is not understood.

Most C. elegans glia are located in symmetric groups of sense organs in the head, called the inner labial (IL), outer labial (OL), cephalic (CEP), and amphid (AM) sensilla. Each organ contains exactly two glial cell types - the sheath and socket. We focused on the development of the IL socket glial cells which are six-fold radially symmetric, such that there is a dorsal, lateral, and ventral pair of cells (ILsoD, ILsoL/R, ILsoV, respectively). We recently identified specific markers for ILso glia and determined a role for them during dendrite extension of associated sensory neurons (Cebul et al., 2020; Fung et al., 2020). ILso glia develop via convergent differentiation all three pairs of cells arise from distinct lineages that diverge at early stages of embryogenesis (Sulston et al., 1983). Importantly, all three pairs of ILso glia express the same reporter genes and appear as a uniform cluster in single-cell profiling experiments (Packer et al., 2019). In contrast, the three lineage-specific pairs of ILso parent cells cluster separately, suggesting that these progenitors are molecularly distinct. In single cell RNA-sequencing studies, the ILso parent cells could not be identifiably linked to their terminal progeny, and thus were interpreted to develop through a "discontinuous" transcriptional trajectory (Packer et al., 2019). This may be because the transcriptomes of 
ILso parent cells change quickly after their terminal divisions as they undergo convergent differentiation, thus making it difficult to identify factors that are important for this process.

Here, we find a lineage-specific role for the conserved Forkhead transcription factor UNC-130 during the specification of a convergently-derived glial cell type in $C$. elegans. We show that, during embryogenesis, UNC-130 is required for the specification of ILso cells that are derived from one convergent lineage, but is dispensable for the production of ILso cells derived from other lineages. Furthermore, consistent with previous work (Sarafi-Reinach \& Sengupta, 2000), mutations in unc-130 perturb the specification of several cell types that are related by lineage, but not by function. We find that UNC-130 is a transiently expressed transcriptional repressor that acts at the time of birth of the ILsoD glia. The vertebrate homolog of UNC-130, FoxD3, also acts in a lineage-specific manner and is required for the specification of neural crest-derived cell types (Kos et al., 2001; Lister et al., 2006; Stewart et al., 2006). Intriguingly, we find that UNC-130 and FoxD3 share molecular features, including their preferred binding sites, and FoxD3 can functionally replace UNC-130. Our results highlight a novel example in which cells that appear as a single cell type arise developmentally from distinct lineages by following convergent paths that require different regulatory factors. Lineage-specific regulatory factors like UNC-130/FoxD3 may represent an evolutionarily ancient mechanism for cell fate specification. 


\section{RESULTS}

\section{unc-130 mutants display defects in convergent differentiation}

To identify genes controlling ILso glial fate, we performed a chemical mutagenesis screen and isolated a mutant strain in which one pair of ILso cells was missing marker expression (see Methods). Genetic mapping and sequencing revealed a causal mutation in the $u n c-130$ gene, which encodes a conserved Forkhead transcription factor. We obtained the reference allele for this gene, the deletion strain ev505, and characterized sense organ perturbations in detail (Nash et al., 2000). We find that 100\% of unc-130 mutants lost expression of ILso markers ( $\mathrm{grl}-18$ pro, col-53 pro, and col-177 pro) specifically in one or both dorsal ILso glia (ILsoD), but not in lateral (ILsoL/R) or ventral (ILsoV) glia (Fig. 1C-G, Table 1; see Methods) (Cebul et al., 2020; Fung et al., 2020). Specification of the six associated IL2 neurons was unaffected, and lack of specific reporters precluded examination of IL sheath glia.

Loss of marker expression in ILsoD glia in unc-130 mutants could be due to defects in the cell division pattern of the lineage that normally produces these cells. For example, the progenitor cell could fail to divide, or the presumptive ILsoD cells could undergo cell death. To test these possibilities, we performed lineaging analysis on unc130 mutants to track all cell divisions in this sublineage. In 8/8 unc-130 mutant embryos, we found that ILsoD progenitors divide to produce presumptive ILsoD glia and their sister cell, the skin cell hyp3 (Fig. S1). However, we found that the timing of this cell division was delayed compared to wild-type embryos. Cell cycle lengths of the other ILso progenitor cells were also slightly delayed in unc-130 mutants, although these cells were not as strongly affected as ILsoD progenitors (Fig. S1). These results provide evidence 
that the putative ILsoD cells are born at approximately the right time in unc-130 mutants, although the ILsoD progenitor may be abnormal as reflected by its delayed cell division. We conclude that loss of marker expression in ILsoD glia in unc-130 mutants is likely due to a loss of identity, rather than changes in the division patterns of the ILsoD lineage.

\section{UNC-130 is required to produce cell types that are related by lineage, not by identity or function}

We wanted to determine whether UNC-130 acts in ILsoD glia specifically or more broadly at the level of a sublineage. Previous work showed that UNC-130 is required for the specification of three sensory neurons (AWA, ASG, and ASI) that are produced by an exclusively neuronal sublineage that is most closely related to the ILsoD sublineage (Fig. 2A) (Sarafi-Reinach and Sengupta, 2000). This left open the possibility that UNC-130 is specific to neuronal fates. In contrast, the ILsoD sublineage is multipotent, giving rise to two types of glia, a neuron, and a skin cell (Fig. 2A) (Sulston et al., 1983).

To systematically determine the requirement for UNC-130 in the ILsoD sublineage, we examined markers of each cell type: the hyp3 skin cell, the URB neuron, and the amphid sheath (AMsh) glial cell (Fig. 2A). In wild-type animals, there are two hyp3 cells whose cell bodies are located dorsally and fuse to form a syncytium. We identified ceh-10pro:GFP as a hyp3-specific marker and found that in 14\% of unc-130 mutants, one or sometimes both hyp3 cells lacked marker expression (Packer et al., 2019) (Fig. 2B,C, Table 2). Next, we identified a unique marker for the sensory neuron URB (nlp-6pro:GFP), which forms a bilateral pair on either side of the head (Fig. 2D). 
Specification of URB appeared unaffected in $u n c-130$ mutant animals, as these cells exhibited unchanged expression of $n l p-6$ pro:GFP (Fig. 2E, Table 2) (Packer at el, 2019). In contrast, specification of AMsh glial cells, which are sister cells of URB and are found in the bilaterally symmetric amphid sense organ, was affected, with $38 \%$ of unc- 130 mutants failing to express an AMsh specific marker, F16F9.3, in one or occasionally both cells (Fig. 2F,G). Loss of F16F9.3 expression was highly correlated with loss of two other AMsh glia-specific markers, T02B11.3pro:GFP and F53F4.13pro:GFP (Bacaj et al., 2008; Fung et al., 2020; Wallace et al., 2016) (Fig. S2). Thus, we find that the specification of non-neuronal cell types that are derived from the ILsoD sublineage is affected in the absence of UNC-130.

Cell types that share an identity, for example neurons that express the same neurotransmitter, often express the same combination of transcription factors. To test whether UNC-130 affects cell types that are functionally related to ILso, we examined markers for other glial cell types. We found no defects in the specification of the four cephalic sheath glia (CEPsh); two phasmid sheath glia (PHsh), which are the functional equivalent of the AMsh glia in the tail and express many of the same markers; or four phasmid socket glia (PHso) (Fig. 2H,I, L-O, Table 2) (Fung et al., 2020; McMiller \& Johnson, 2005; Yoshimura et al., 2008). Surprisingly, we observed extra amphid socket (AMso) glia in unc-130 mutants, with $42 \%$ of mutant animals expressing the AMsospecific marker, grl-2, in an extra cell (Fig. 2J, K, Table 2) (Hao et al., 2006). We found that expression of $g r l-2$ in the extra cell was highly correlated with expression of two other AMso-specific markers, lin-48 and itr-1 (Fig. S2) (Fung et al., 2020; Heiman \& Shaham, 2009; Johnson et al., 2001). In contrast to endogenous AMso cells, which are 
positioned laterally, extra AMso cells were located dorsally, consistent with the position of the missing ILsoD and hyp3 cells (Fig. S2). These observations suggest that in the absence of UNC-130, mis-specified cells may take on alternative fates. Taken together, we find that defects in fate specification in $u n c-130$ mutants are not solely related to a particular cell's identity or function, but rather to cell types that share a lineage origin.

\section{UNC-130 acts in lineage-specific progenitors and newly-born precursor cells}

Due to its broad effects on several cell types arising from the same sublineage, ee reasoned that, unlike terminal selectors, UNC-130 might act earlier in development. Indeed, previous work showed that UNC-130 is expressed in the immediate progenitors of affected sensory neurons (Sarafi-Reinach \& Sengupta, 2000). We examined a translational reporter strain in which UNC-130 was fused with GFP and acquired a time course of images during C. elegans embryogenesis (Sarov et al., 2006). Consistent with previous work and our lineaging experiments, UNC-130:GFP is brightly expressed at early stages of development ( $\sim 300 \mathrm{~min}$ to $500 \mathrm{~min})$, and starts to wane as animals near hatching at 3-fold stages $(550+\mathrm{min})$ (Fig. 3A-G). In contrast, expression of the IL socket-specific marker, $g r l-18$, is not detectable at early stages, starts to be expressed in 2-fold embryos (500 min), and stays on into adulthood (Fig. 3H-N). These results provide evidence that unc-130 is expressed early in development, in progenitor cells and presumptive ILso cells after they are born, but its expression is downregulated as these cells differentiate.

We wanted to understand why mutation of $u n c-130$ affects the specification of the ILsoD pair of glia, but not the equivalent lateral or ventral pairs. We noted that the 
lineages that give rise to the three pairs of ILso glia diverge at the 4- and 16-cell stages

(Fig. 3O) (Sulston et al., 1983). Previous studies showed that unc-130 expression commences midway through embryogenesis in an ABp-derived lineage that gives rise to dorsal - but not lateral or ventral - ILso glia (Murray et al., 2012; Sarafi-Reinach and Sengupta, 2000). To better define this expression pattern, we performed UNC-130 lineaging experiments and extended the period of data acquisition to capture the birth of the presumptive ILso cells. We found that $u n c-130$ is highly expressed in the ILsoD lineage and in the presumptive ILsoD cell after it is born, but not in the lineages that give rise to the ILsoL/R or ILsoV cells (Fig. 3P). We did note low but increasing levels of expression in ILsoV glia after they are born. The significance of this is unclear, as ILsoV glia are specified normally in $u n c-130$ mutants. Taken together, these findings show that UNC-130 is expressed highly in the progenitor that gives rise to the ILsoD glia around the time when the cells are born.

To functionally address when UNC-130 is required for fate specification, we used early and late promoters to drive $u n c-130$ expression in $u n c-130$ mutants and determined the extent of rescue of glial specification defects. For early rescue, we used a regulatory sequence we identified upstream of $m n m-2$, a gene which similarly to $u n c-130$ is expressed early in the ILsoD sublineage but not in other lineages that normally express unc-130 (Fig. S3) (Murray et al., 2012). For late rescue, we used a sequence upstream of mir-228, which is expressed in all glial cells shortly after they are born (Fig. S3) (Fung et al., 2020; Pierce et al., 2008). We find that early unc-130 expression under the $m n m-2$ promoter in $u n c-130$ mutants rescues specification of ILsoD glia almost as completely as expression driven by the unc-130 promoter (Fig. 3Q). In contrast, late expression of unc- 
130 driven by the mir-228 promoter does not rescue specification defects (Fig. 3Q). Intriguingly, expression of mir-228pro:unc-130 in unc-130 mutants resulted in a mild enhancement of specification defects, suggesting that downregulation of unc-130 in newly-born cells is important for fate specification.

In a complementary approach, we drove $u n c-130$ expression using a heat-shock inducible promoter in $u n c-130$ mutants to define a temporal window during which UNC130 is required for fate specification. We found that heat-shock induction of UNC-130 at early stages of development resulted in a high lethality rate, therefore, we scored arrested embryos or larvae 12-18 hours after heat shock. Heat-shock induced expression of unc130 at $\sim 150$ min (see Methods), before the birth of the ILsoD, resulted in moderate rescue with $48 \%$ of animals expressing grl-18 in one or two ILsoD cells as compared to $12 \%$ of animals expressing grl-18 in one ILsoD cell in no heat-shock controls (Fig. 3R). Heat-shock-induced expression of $u n c-130$ at approximately the birth of ILsoD glia resulted in the strongest rescue of fate specification defects with $62 \%$ of animals expressing grl-18 in one or two ILsoD glia (Fig. 3R). Heat-shock induction after $\sim 350$ min, which is after the ILsoD cells are born but before they start to differentiate, or any other later time points, did not result in significant rescue of specification defects as compared to no heat-shock controls (Fig. 3R).

Together these results provide evidence that $u n c-130$ acts transiently as ILsoD progenitors are dividing to produce ILsoD glia and shortly after these cells are born, but it cannot rescue specification defects after this temporal window has passed. This temporal requirement for UNC-130 before the onset of differentiation suggests that rather than directly instructing cell fate, UNC-130 establishes competency for fate specification. 


\section{UNC-130 functions as a repressor}

The UNC-130 homolog FoxD3 acts as a repressor in several developmental contexts, in some cases recruiting the Groucho repressor complex through a conserved engrailed homology (eh1) domain (Ono et al., 2014; Yaklichkin, Steiner, et al., 2007). Paradoxically, FoxD3 also functions as a pioneer factor in embryonic stem cells and during early neural crest specification (Krishnakumar et al., 2016; Lukoseviciute et al., 2018). To determine whether UNC-130 acts as a repressor or an activator during convergent differentiation, we expressed synthetic constructs encoding the UNC-130 DNA-binding domain (DBD) protein fused to a canonical activator (VP64 - four copies of VP16 activator domain) or repressor (Drosophila Engrailed domain) under the unc130 promoter in an unc-130 mutant strain and assessed rescue of glia specification defects (Fig. 4A,B). Expression of full-length UNC-130 fully rescued ILsoD glia defects (Fig. 4B). Expression of the UNC-130 DBD alone or a DBD-VP64 synthetic activator showed no rescue (Fig. 4B). In contrast, the synthetic repressor DBD-Engrailed substantially rescued ILsoD specification defects, suggesting that UNC-130 normally functions as a transcriptional repressor (Fig. 4B).

The vertebrate UNC-130 homolog, FoxD3, contains an eh1 motif in its carboxyterminal domain that recruits the Groucho repressive complex. This region of UNC-130 is not conserved, but we identified a candidate eh1 sequence in the UNC-130 aminoterminal domain and tested whether it might act similarly (Yaklichkin, Vekker, et al., 2007) (Fig. 4A, S5). Surprisingly, deletion of the eh1 domain from full-length UNC-130 resulted in rescue of specification defects, due to a redundant function of the carboxyterminus as discussed below (Fig. 4B). We found that expression of a protein containing 
the UNC-130 amino-terminus and DBD partially rescues ILsoD defects, and the candidate ehlinteraction motif is necessary for this rescuing function (Fig. 4B).

Interestingly, expression of the DBD with the carboxy-terminus also rescues all glial specification defects, which suggests it might contain previously unidentified repressor motifs as well (Fig. 4A, B). Using luciferase assays in cultured mammalian cells, we found that N-term:GAL4DBD:C-term and GAL4DBD:C-term have reduced reporter activity compared to GAL4 DBD alone (Fig. S4), consistent with the carboxyterminus harboring repressive activity. Thus, we find that UNC-130 promotes ILsoD fate by acting as a transient transcriptional repressor at the time when these glial cells are being produced. One possibility is that UNC-130 directly represses genes that would activate alternative fates, allowing presumptive ILsoD glia to follow the correct transcriptional trajectory.

\section{UNC-130 and the neural crest determinant FoxD3 share a conserved function}

The UNC-130 DBD is highly conserved with its vertebrate homolog, FoxD3 (Fig. 5A, S5), thus we wanted to determine if they share DNA-binding specificities. Different Forkhead transcription factors can bind to a consensus primary motif RYAAAYA (FkhP), a related secondary motif AHAACA (FkhS), or an unrelated alternate motif GACGC (FHL) (Nakagawa et al., 2013). To determine its binding specificity, we incubated recombinant UNC-130-DBD protein with universal protein binding microarrays (PBMs) containing all possible 10-mer double-stranded DNA sequences (Berger et al., 2006). We find that UNC-130-DBD preferentially binds $[\mathrm{A} / \mathrm{G}][\mathrm{T} / \mathrm{C}] \mathrm{AAACA}$ and $\mathrm{AA}[\mathrm{T} / \mathrm{C}] \mathrm{AACA}$ sequences, variants of the primary and 
secondary Forkhead binding motifs, respectively, consistent with it behaving as a conserved Forkhead family member (Fig. 5B).

From our mutant screen and previous studies, we assembled a collection of point mutations in the UNC-130 DBD: ns313 - W201; oy10 and ev659 - R218; op459 - R219 (Nash et al., 2000; Sarafi-Reinach \& Sengupta, 2000) (Fig. 5A, S5). Mapped onto the FoxD3 structure, W201 is located in a $\beta$-sheet that flanks the central helical bundle that inserts into the major groove of DNA, whereas the R218 and R219 residues are in a wing domain on the opposite side of the helix bundle (Fig. 5C). To assess the effect of the W201G and R218C point mutations, we applied mutant UNC-130 recombinant proteins separately onto PBMs. We found that the R218C protein still preferentially binds DNA sequences recognized by wild-type UNC-130 but with lower affinity (Fig. 5D, S5), while the W201G mutant protein did not exhibit sequence-specific preferences for these or any other motifs, suggesting severely impaired DNA binding (Fig. 5D, S5). These binding defects strongly correlated with in vivo function. The W201G mutant exhibited defects in ILsoD specification that are nearly as strong as an early stop mutant (R62stop) or a deletion allele, such that $>90 \%$ of ILsoD glia lose reporter expression (Fig. 5E). In contrast, in hypomorphic alleles, which include R218C, R218H, R219K, only 50\% of ILsoD glia lose reporter expression (Fig. 5E). Thus, moderately impaired DNA binding appears to promote weak ILsoD glial defects, and severely impaired DNA binding results in strong ILsoD glial defects. We find that these highly conserved amino acid residues are crucial for UNC-130 function, and are likely to similarly disrupt FoxD3 function in vertebrates. 
In vertebrates, FoxD3 is required for the specification of several cell types that arise from the neural crest, a multipotent lineage that participates in convergent differentiation (Dottori et al., 2001; Kos et al., 2001; Lister et al., 2006; Lukoseviciute et al., 2018; Sasai et al., 2001; Stewart et al., 2006; Teng et al., 2008). Although examination of UNC-130 and human FOXD3 protein sequences revealed little similarity outside of the highly-conserved DBD and eh1 motif (Fig. 5A, S5), we found that expression of an unc-130 promoter::FOXD3 cDNA transgene almost completely rescues ILsoD glial specification defects in $u n c-130$ mutants (Fig. 5F). This suggests that UNC130 and FoxD3 functionality is conserved despite divergence at the primary sequence level.

In summary, although $C$. elegans lacks a neural crest, the similarities between FoxD3 and UNC-130 extend from their roles in lineage specification to their molecular mechanisms of action - including their preferred DNA binding sites and their roles as transcriptional repressors, likely via an interaction with the Groucho repressive complex. More broadly, our results lead to the speculation that prior to the evolution of the neural crest, there already existed a FoxD3 precursor that acted in a multipotent sublineage that exhibits convergent differentiation.

\section{DISCUSSION}

Unraveling the mechanisms that establish fate competence in progenitors and precursors is critical to understanding how developmental lineage is coupled to cell fate why do certain cell types arise only from particular lineages? The special case of convergent differentiation promises to offer important insights into this relationship. 
An implication of our findings and previous studies is that different progenitors can take distinct transcriptional paths to produce the same cell type. We find that UNC130 is only required in one of three convergent lineages to produce the ILso glial cell type. Although convergent differentiation was not their focus, previous studies provide additional examples. For example, loss of $m l s-2 / \mathrm{Nkx}$ affects mainly ventral, but not dorsal, CEPsh glia (Yoshimura et al., 2008). Similar to ILso glia, dorsal and ventral CEPsh glia are derived from lineages that diverge early in development. MLS-2 also appears to function at the lineage level, as other studies have determined that cell types related to CEPshV glia by lineage are mis-specified in $m l s-2$ mutants (Abdus-Saboor et al., 2012; Kim et al., 2010). Other examples include the requirement for LIN-32 to specify dorsal but not ventral CEP neurons, and CEH-10 to specify dorsal but not lateral or ventral RME neurons (Doitsidou et al., 2010; Forrester et al., 1998; Rojo Romanos et al., 2017). These observations provide tantalizing starting points for characterizing other factors that are involved in convergent differentiation.

Cell-type specification in terminally differentiating cells, which is mediated by master regulator transcription factors called terminal selectors, has been extensively studied in a number of cell types (Hobert \& Kratsios, 2019). In contrast, factors that act transiently in progenitor cells to establish lineage-specific identity are less wellunderstood. Some candidates for this type of factor include CEH-36 and UNC-30, which function redundantly to regulate progenitor cell cycle progression and cell position in a number of developmental lineages (Walton et al., 2015), and CND-1, which regulates mitotic progression and establishment of neuronal fate in lineages that will give rise to neurons (Hallam et al., 2000). Another example is the lineage-restricted transcription 
factor TBX-37/38, which is expressed transiently early in embryogenesis to prime a locus that does not become active until several cell cycles later in the mature cell type (Charest et al., 2020; Cochella \& Hobert, 2012). Similarly, in this study, we find that UNC-130 acts in lineage-related progenitor cells before these cells make terminal divisions and their progeny start to differentiate. Therefore, the function of these early-acting factors is likely to establish competency for fate specification, a role which differs from that of terminal selectors.

How does UNC-130 establish fate competency in a specific lineage? UNC-130 is required broadly for the specification of several unrelated cell types produced by the ILsoD sublineage. It is possible that UNC-130 primes and represses cell type-specific loci in each progenitor cell based on cellular context and binding partners. Alternatively, it may not impart any specific cell type information, but rather functions to transition progenitor cells to a more restricted state through the repression of pluripotency genes. Alternatively, or in addition, it may block off paths to alternate fates by repressing target genes that need to remain inactive in a particular lineage.

The results presented in this study are highly relevant to understanding the relationship between lineage and cell fate in the vertebrate nervous system, an intricate structure comprising many diverse cell types arising from a myriad of lineages. Singlecell RNA profiling of the mammalian brain has shown that the glial classes of astrocytes and microglia, which had long been thought to consist of molecularly homogeneous cells, actually exhibit striking region-specific molecular heterogeneity (Hammond et al., 2019; John Lin et al., 2017; Marques et al., 2016; Masuda et al., 2019; Morel et al., 2017; Spitzer et al., 2019; Zeisel et al., 2015, 2018). In contrast, the molecular signatures of 
oligodendrocytes are highly similar (Marques et al., 2018; Zeisel et al., 2018). Because astrocytes and oligodendrocytes are thought to share a common progenitor, these observations suggest that regionally distinct progenitor cells may undergo convergent differentiation in the mammalian nervous system as well. Elucidation of these pathways will require single-cell profiling methods to be combined with careful lineage tracing and functional perturbation of regulatory factors in vivo to ultimately achieve the level of resolution that is available in the far simpler nervous system of C. elegans.

\section{ACKNOWLEDGMENTS}

We thank Laura Moriarty for assistance with the genetic screen that isolated $n s 313$; Oliver Hobert for whole genome sequencing; Piali Sengupta for unc-130 cDNA and the oy10 mutant strain; Joseph Culotti for unc-130 mutant strains; Raphael Bruckner for assistance with cell culture; and Constance Cepko, Christopher Walsh, and the members of the Heiman laboratory for comments and advice on the manuscript. Some strains were provided by the CGC, which is funded by NIH Office of Research Infrastructure Programs (P40 OD010440).

\section{FUNDING}

This project was supported by a William Randolph Hearst fellowship to K.M.;

Bioinformatics and Integrative Genomics training grant T32HG002295 from NHGRI and National Science Foundation Graduate Research fellowship to J.M.R.; R01HG003985 and R01HG010501 from NIH/NHGRI to M.L.B; R35NS105094 from NIH/NINDS to 
S.S.; R35GM127093 from NIH/NIGMS to J.I.M; and a William F. Milton Award to M.G.H.

\section{AUTHOR CONTRIBUTIONS}

Conceptualization: K.M. and M.G.H.; Experimental design: K.M. and M.G.H.; PBM experiment and analysis: J.M.R.; Lineaging analysis: J.D.R. and J.I.M.; Writing of manuscript: K.M. and M.G.H. with input from all authors; Supervision and funding: S.S., M.L.B., J.I.M. and M.G.H.

\section{COMPETING INTERESTS}

M.L.B. is a co-inventor on patents on PBM technology. All other authors declare no other competing interests.

\section{MATERIALS AND METHODS \\ Strains}

Strains were constructed in the N2 background and cultured under standard conditions (Brenner, 1974). Transgenic strains were generated with standard techniques (Mello \& Fire, 1995) with injection of $100 \mathrm{ng} / \mu \mathrm{L}$ of DNA (5-50 $\mu \mathrm{L}$ per plasmid). Strains, transgenes, and plasmids are listed in Supp. Tables 1-3 respectively.

\section{Isolation and mapping of unc-130 alleles}

We isolated an allele of $u n c-130, n s 313$, from a genetic screen for sense organ abnormalities. Animals of genotype oyIs $44 \mathrm{~V}$ were mutagenized using $70 \mathrm{mM}$ ethyl 
methanesulfonate (EMS, Sigma) at $20^{\circ} \mathrm{C}$ for 4 hours. Nonclonal F2 progeny were examined on an Axioplan 2 fluorescence microscope (Zeiss) with 633/1.4 NA objective (Zeiss) and dual-band filter set (Chroma, Set 51019) and animals with sense organ defects were recovered. A mutant strain, $n s 313$, exhibiting short amphid dendrites (14\% penetrance) and amphid sheath migration defects (55\% penetrance) was isolated.

With standard linkage mapping and SNP analysis (Wicks et al., 2001), ns313 was mapped to an interval between $-6 \mathrm{cM}$ and $15 \mathrm{cM}$ on LG II. $n s 313$ animals were crossed to the Hawaiian strain CB4856 and F2 progeny with the mutant phenotype were transferred to individual plates. All F3 recombinants were pooled and subjected to genomic DNA extraction and whole-genome sequencing for one-step mapping (Doitsidou et al., 2010). Analysis with CloudMap (Minevich et al., 2012) identified a linked region on LG II including a point mutation in $u n c-130$ (GAACTAT[T>G]GGGCGTGGA) (W201G).

\section{Characterization of glial phenotypes}

To score regional defects in IL sockets, we generated strains that co-expressed the IL socket marker (hmnIs47 [grl-18pro:mApple]) with a marker for URX (ynIs48 [flp8pro:GFP]), a dorsally located neuron whose dendrites fasciculate with the processes of the dorsal, but not lateral or ventral, IL sockets as a landmark. Glial specification defects were scored visually on either a Nikon SMZ1500 stereomicroscope with an HR Plan Apo 1.6x objective or a Deltavision Core imaging system (Applied Precision) with UApo/340 40x 1.35NA objective (Olympus). 


\section{Fluorescence microscopy and image processing}

Animals were mounted on 2\% agarose pads in M9 buffer (Sulston et al., 1983) with 50$100 \mathrm{mM}$ sodium azide depending on developmental stage, and imaged using a Deltavision Core imaging system (Applied Precision) with UApo/340 40x 1.35NA, PlanApo 60x 1.42NA, and U-PlanApo 100x 1.4NA objectives (Olympus) and CoolSnap HQ2 camera. Images were deconvolved using Softworx (Applied Precision) and maximum-brightness projections were obtained from contiguous optical sections using ImageJ.

\section{Lineaging analysis}

Cell lineage analysis was performed using the StarryNite/AceTree cell tracking system (Bao et al., 2006; Boyle et al., 2006; Santella et al., 2010). Embryos from strains RW11144, CHB4067 [ev505 ujIs113; wgIs476], and CHB3933 [ujIs113; wgIs746] were imaged on a Leica SP5 resonance-scanning confocal microscope with approximately $1 \frac{1}{2}$ minute time point spacing and 0.5 micron z-resolution as previously described (Richards et al., 2013). Computational cell tracking of histone-mCherry images was used to track cells across time and identify the time of all terminal divisions in the lineages leading to ILsoD (ABp(1/r)aapa), ILsoL/R (ABalaaap) and ILsoV (ABalppap and ABarappp).

\section{Heat-shock induced expression}

Strain CHB4158 [ev505; hmnEx2283 [hsp16-2pro:unc-130 + hsp16-41pro:unc-130+ grl-18pro:YFP + unc-122pro:RFP]] was grown at $20^{\circ} \mathrm{C}$ prior to heat-shock experiments.

Age of embryos was determined by morphological state. Embryos at different 
developmental stages were sorted onto separate plates and heat-shocked at $34^{\circ} \mathrm{C}$ for 60 min to induce expression of UNC-130. After heat-shock, animals were grown at $20^{\circ} \mathrm{C}$ for 12-18 hours and embryo and larvae were scored for $g r l-18$ pro:YFP expression by fluorescence microscopy as described above.

\section{PBM experiments and data analysis}

PBM experiments were performed on universal "all-10-mer" arrays in 8X60K format (Agilent, AMADID 030236) (Berger et al., 2006; Nakagawa et al., 2013). PBM experiments were performed at $500 \mathrm{nM}$ protein concentration in the standard protein binding reaction mixture, substituting buffer A for PBS (buffer A= $138 \mathrm{mM} \mathrm{KGlu}, 12$ $\mathrm{mM} \mathrm{NaHCO} 3,0.8 \mathrm{mM} \mathrm{MgCl}_{2}, \mathrm{pH}$ 7.2) in the standard PBM protocol (Berger \& Bulyk, 2009). Protein binding was detected with an Alexa488-conjugated anti-GST antibody (Life Technologies A-11131), and arrays were scanned using a GenePix 4400A (Molecular Devices) microarray scanner. Binding was quantified using the Universal PBM Analysis Suite (Berger \& Bulyk, 2009) to generate E-scores for each 8-mer. Motifs were derived using the Seed-and-Wobble algorithm (Berger et al., 2006; Berger \& Bulyk, 2009). Two replicate experiments were performed, with replicate 1 having higher Escores overall. Replicate 1 is shown in the main body Fig. 5, and Replicate 2 is shown in supplemental Fig. S5.

Boxplots were generated in $\mathrm{R}$, from the E-scores of the 8-mer sequences that match the UNC-130 FkhP motif ([AG][CT]AAACA) or the FkhS motif $(\mathrm{AA}[\mathrm{CT}] \mathrm{AACA})$. Individual data points are displayed on the boxplots using the stripchart function in R. Significant differences in binding were evaluated using a one-sided Mann- 
Whitney test, with the wilcox.test function in R. All PBM raw data will be available on

UniPROBE: http://thebrain.bwh.harvard.edu/uniprobe/ with deposition ID MIZ19A

\section{Luciferase assays}

HEK293T cells were cultured at $37^{\circ} \mathrm{C}$ and transfected with Fugene (Roche). 48 hours

post transfection, cells were collected in cold 1X PBS and transferred into 96-well plates.

Renilla and firefly luciferase activity were assayed according to manufacturer's

instructions using the Dual-Glo assay (Promega) and bioluminescence was collected on a

Molecular Devices Spectramax Paradigm plate reader. Firefly luciferase activity was

normalized to renilla luciferase activity in each sample. 


\section{REFERENCES}

Abdus-Saboor, I., Stone, C. E., Murray, J. I., \& Sundaram, M. V. (2012). The

Nkx5/HMX homeodomain protein MLS-2 is required for proper tube cell shape in the C. elegans excretory system. Developmental Biology, 366(2), 298-307. https://doi.org/10.1016/j.ydbio.2012.03.015

Bacaj, T., Tevlin, M., Lu, Y., \& Shaham, S. (2008). Glia are essential for sensory organ function in C. elegans. Science (New York, N.Y.), 322(5902), 744-747. https://doi.org/10.1126/science. 1163074

Bao, Z., Murray, J. I., Boyle, T., Ooi, S. L., Sandel, M. J., \& Waterston, R. H. (2006). Automated cell lineage tracing in Caenorhabditis elegans. Proceedings of the National Academy of Sciences of the United States of America, 103(8), 27072712. https://doi.org/10.1073/pnas.0511111103

Berger, M. F., \& Bulyk, M. L. (2009). Universal protein-binding microarrays for the comprehensive characterization of the DNA-binding specificities of transcription factors. Nature Protocols, 4(3), 393-411. https://doi.org/10.1038/nprot.2008.195

Berger, M. F., Philippakis, A. A., Qureshi, A. M., He, F. S., Estep, P. W., \& Bulyk, M. L. (2006). Compact, universal DNA microarrays to comprehensively determine transcription-factor binding site specificities. Nature Biotechnology, 24(11), 1429-1435. https://doi.org/10.1038/nbt1246

Boyle, T. J., Bao, Z., Murray, J. I., Araya, C. L., \& Waterston, R. H. (2006). AceTree: A tool for visual analysis of Caenorhabditis elegans embryogenesis. $B M C$ Bioinformatics, 7, 275. https://doi.org/10.1186/1471-2105-7-275

Brenner, S. (1974). The genetics of Caenorhabditis elegans. Genetics, 77(1), 71-94. 
Cebul, E. R., McLachlan, I. G., \& Heiman, M. G. (2020). Dendrites with specialized glial attachments develop by retrograde extension using SAX-7 and GRDN-1. Development (Cambridge, England), 147(4). https://doi.org/10.1242/dev.180448

Chan, M. M., Smith, Z. D., Grosswendt, S., Kretzmer, H., Norman, T. M., Adamson, B., Jost, M., Quinn, J. J., Yang, D., Jones, M. G., Khodaverdian, A., Yosef, N., Meissner, A., \& Weissman, J. S. (2019). Molecular recording of mammalian embryogenesis. Nature, 570(7759), 77-82. https://doi.org/10.1038/s41586-019$1184-5$

Charest, J., Daniele, T., Wang, J., Bykov, A., Mandlbauer, A., Asparuhova, M., Röhsner, J., Gutiérrez-Pérez, P., \& Cochella, L. (2020). Combinatorial Action of Temporally Segregated Transcription Factors. Developmental Cell. https://doi.org/10.1016/j.devcel.2020.09.002

Cochella, L., \& Hobert, O. (2012). Embryonic priming of a miRNA locus predetermines postmitotic neuronal left/right asymmetry in C. elegans. Cell, 151(6), 1229-1242. https://doi.org/10.1016/j.cell.2012.10.049

Doitsidou, M., Poole, R. J., Sarin, S., Bigelow, H., \& Hobert, O. (2010). C. elegans mutant identification with a one-step whole-genome-sequencing and SNP mapping strategy. PloS One, 5(11), e15435. https://doi.org/10.1371/journal.pone.0015435

Dottori, M., Gross, M. K., Labosky, P., \& Goulding, M. (2001). The winged-helix transcription factor Foxd3 suppresses interneuron differentiation and promotes neural crest cell fate. Development (Cambridge, England), 128(21), 4127-4138. 
Dupin, E., Calloni, G. W., Coelho-Aguiar, J. M., \& Le Douarin, N. M. (2018). The issue of the multipotency of the neural crest cells. Developmental Biology, 444 Suppl 1, S47-S59. https://doi.org/10.1016/j.ydbio.2018.03.024

Forrester, W. C., Perens, E., Zallen, J. A., \& Garriga, G. (1998). Identification of Caenorhabditis elegans genes required for neuronal differentiation and migration. Genetics, 148(1), 151-165.

Fung, W., Wexler, L., \& Heiman, M. G. (2020). Cell-type-specific promoters for C. elegans glia. Journal of Neurogenetics, 1-12. https://doi.org/10.1080/01677063.2020.1781851

Hallam, S., Singer, E., Waring, D., \& Jin, Y. (2000). The C. elegans NeuroD homolog cnd-1 functions in multiple aspects of motor neuron fate specification. Development (Cambridge, England), 127(19), 4239-4252.

Hammond, T. R., Dufort, C., Dissing-Olesen, L., Giera, S., Young, A., Wysoker, A., Walker, A. J., Gergits, F., Segel, M., Nemesh, J., Marsh, S. E., Saunders, A., Macosko, E., Ginhoux, F., Chen, J., Franklin, R. J. M., Piao, X., McCarroll, S. A., \& Stevens, B. (2019). Single-Cell RNA Sequencing of Microglia throughout the Mouse Lifespan and in the Injured Brain Reveals Complex Cell-State Changes. Immunity, 50(1), 253-271.e6. https://doi.org/10.1016/j.immuni.2018.11.004

Hao, L., Johnsen, R., Lauter, G., Baillie, D., \& Bürglin, T. R. (2006). Comprehensive analysis of gene expression patterns of hedgehog-related genes. BMC Genomics, 7, 280. https://doi.org/10.1186/1471-2164-7-280 
Heiman, M. G., \& Shaham, S. (2009). DEX-1 and DYF-7 establish sensory dendrite length by anchoring dendritic tips during cell migration. Cell, 137(2), 344-355. https://doi.org/10.1016/j.cell.2009.01.057

Hobert, O., \& Kratsios, P. (2019). Neuronal identity control by terminal selectors in worms, flies, and chordates. Current Opinion in Neurobiology, 56, 97-105. https://doi.org/10.1016/j.conb.2018.12.006

Jin, C., Marsden, I., Chen, X., \& Liao, X. (1999). Dynamic DNA contacts observed in the NMR structure of winged helix protein-DNA complex. Journal of Molecular Biology, 289(4), 683-690. https://doi.org/10.1006/jmbi.1999.2819

John Lin, C.-C., Yu, K., Hatcher, A., Huang, T.-W., Lee, H. K., Carlson, J., Weston, M. C., Chen, F., Zhang, Y., Zhu, W., Mohila, C. A., Ahmed, N., Patel, A. J., Arenkiel, B. R., Noebels, J. L., Creighton, C. J., \& Deneen, B. (2017). Identification of diverse astrocyte populations and their malignant analogs. Nature Neuroscience, 20(3), 396-405. https://doi.org/10.1038/nn.4493

Johnson, A. D., Fitzsimmons, D., Hagman, J., \& Chamberlin, H. M. (2001). EGL-38 Pax regulates the ovo-related gene lin-48 during Caenorhabditis elegans organ development. Development (Cambridge, England), 128(15), 2857-2865.

Keyte, A., \& Hutson, M. R. (2012). The neural crest in cardiac congenital anomalies. Differentiation; Research in Biological Diversity, 84(1), 25-40. https://doi.org/10.1016/j.diff.2012.04.005

Kim, K., Kim, R., \& Sengupta, P. (2010). The HMX/NKX homeodomain protein MLS-2 specifies the identity of the AWC sensory neuron type via regulation of the ceh- 
36 Otx gene in C. elegans. Development (Cambridge, England), 137(6), 963-974. https://doi.org/10.1242/dev.044719

Kos, R., Reedy, M. V., Johnson, R. L., \& Erickson, C. A. (2001). The winged-helix transcription factor FoxD3 is important for establishing the neural crest lineage and repressing melanogenesis in avian embryos. Development (Cambridge, England), 128(8), 1467-1479.

Krishnakumar, R., Chen, A. F., Pantovich, M. G., Danial, M., Parchem, R. J., Labosky, P. A., \& Blelloch, R. (2016). FOXD3 Regulates Pluripotent Stem Cell Potential by Simultaneously Initiating and Repressing Enhancer Activity. Cell Stem Cell, 18(1), 104-117. https://doi.org/10.1016/j.stem.2015.10.003

Kwon, G. S., Viotti, M., \& Hadjantonakis, A.-K. (2008). The endoderm of the mouse embryo arises by dynamic widespread intercalation of embryonic and extraembryonic lineages. Developmental Cell, 15(4), 509-520. https://doi.org/10.1016/j.devcel.2008.07.017

Lister, J. A., Cooper, C., Nguyen, K., Modrell, M., Grant, K., \& Raible, D. W. (2006). Zebrafish Foxd3 is required for development of a subset of neural crest derivatives. Developmental Biology, 290(1), 92-104. https://doi.org/10.1016/j.ydbio.2005.11.014

Liu, X., Chen, W., Li, W., Li, Y., Priest, J. R., Zhou, B., Wang, J., \& Zhou, Z. (2019). Single-Cell RNA-Seq of the Developing Cardiac Outflow Tract Reveals Convergent Development of the Vascular Smooth Muscle Cells. Cell Reports, 28(5), 1346-1361.e4. https://doi.org/10.1016/j.celrep.2019.06.092 
Lukoseviciute, M., Gavriouchkina, D., Williams, R. M., Hochgreb-Hagele, T.,

Senanayake, U., Chong-Morrison, V., Thongjuea, S., Repapi, E., Mead, A., \&

Sauka-Spengler, T. (2018). From Pioneer to Repressor: Bimodal foxd3 Activity

Dynamically Remodels Neural Crest Regulatory Landscape In Vivo.

Developmental Cell, 47(5), 608-628.e6.

https://doi.org/10.1016/j.devcel.2018.11.009

Marques, S., van Bruggen, D., Vanichkina, D. P., Floriddia, E. M., Munguba, H.,

Väremo, L., Giacomello, S., Falcão, A. M., Meijer, M., Björklund, Å. K., Hjerling-Leffler, J., Taft, R. J., \& Castelo-Branco, G. (2018). Transcriptional Convergence of Oligodendrocyte Lineage Progenitors during Development.

Developmental Cell, 46(4), 504-517.e7.

https://doi.org/10.1016/j.devcel.2018.07.005

Marques, S., Zeisel, A., Codeluppi, S., van Bruggen, D., Mendanha Falcão, A., Xiao, L., Li, H., Häring, M., Hochgerner, H., Romanov, R. A., Gyllborg, D., Muñoz Manchado, A., La Manno, G., Lönnerberg, P., Floriddia, E. M., Rezayee, F., Ernfors, P., Arenas, E., Hjerling-Leffler, J., ... Castelo-Branco, G. (2016).

Oligodendrocyte heterogeneity in the mouse juvenile and adult central nervous system. Science (New York, N.Y.), 352(6291), 1326-1329.

https://doi.org/10.1126/science.aaf6463

Masuda, T., Sankowski, R., Staszewski, O., Böttcher, C., Amann, L., Sagar, null, Scheiwe, C., Nessler, S., Kunz, P., van Loo, G., Coenen, V. A., Reinacher, P. C., Michel, A., Sure, U., Gold, R., Grün, D., Priller, J., Stadelmann, C., \& Prinz, M. (2019). Spatial and temporal heterogeneity of mouse and human microglia at 
single-cell resolution. Nature, 566(7744), 388-392.

https://doi.org/10.1038/s41586-019-0924-X

McKenna, A., \& Gagnon, J. A. (2019). Recording development with single cell dynamic lineage tracing. Development (Cambridge, England), 146(12).

https://doi.org/10.1242/dev.169730

McMiller, T. L., \& Johnson, C. M. (2005). Molecular characterization of HLH-17, a C. elegans bHLH protein required for normal larval development. Gene, 356, 1-10. https://doi.org/10.1016/j.gene.2005.05.003

Mello, C., \& Fire, A. (1995). DNA transformation. Methods in Cell Biology, 48, 451482.

Minevich, G., Park, D. S., Blankenberg, D., Poole, R. J., \& Hobert, O. (2012). CloudMap: A cloud-based pipeline for analysis of mutant genome sequences. Genetics, 192(4), 1249-1269. https://doi.org/10.1534/genetics.112.144204

Morel, L., Chiang, M. S. R., Higashimori, H., Shoneye, T., Iyer, L. K., Yelick, J., Tai, A., \& Yang, Y. (2017). Molecular and Functional Properties of Regional Astrocytes in the Adult Brain. The Journal of Neuroscience: The Official Journal of the Society for Neuroscience, 37(36), 8706-8717. https://doi.org/10.1523/JNEUROSCI.3956-16.2017

Murray, J. I., Boyle, T. J., Preston, E., Vafeados, D., Mericle, B., Weisdepp, P., Zhao, Z., Bao, Z., Boeck, M., \& Waterston, R. H. (2012). Multidimensional regulation of gene expression in the C. elegans embryo. Genome Research, 22(7), 1282-1294. https://doi.org/10.1101/gr.131920.111 
Nakagawa, S., Gisselbrecht, S. S., Rogers, J. M., Hartl, D. L., \& Bulyk, M. L. (2013).

DNA-binding specificity changes in the evolution of forkhead transcription factors. Proceedings of the National Academy of Sciences of the United States of America, 110(30), 12349-12354. https://doi.org/10.1073/pnas.1310430110

Nash, B., Colavita, A., Zheng, H., Roy, P. J., \& Culotti, J. G. (2000). The forkhead transcription factor $\mathrm{UNC}-130$ is required for the graded spatial expression of the UNC-129 TGF-beta guidance factor in C. elegans. Genes \& Development, 14(19), 2486-2500.

Ono, H., Kozmik, Z., Yu, J.-K., \& Wada, H. (2014). A novel N-terminal motif is responsible for the evolution of neural crest-specific gene-regulatory activity in vertebrate FoxD3. Developmental Biology, 385(2), 396-404. https://doi.org/10.1016/j.ydbio.2013.11.010

Packer, J. S., Zhu, Q., Huynh, C., Sivaramakrishnan, P., Preston, E., Dueck, H., Stefanik, D., Tan, K., Trapnell, C., Kim, J., Waterston, R. H., \& Murray, J. I. (2019). A lineage-resolved molecular atlas of C. elegans embryogenesis at single-cell resolution. Science (New York, N.Y.). https://doi.org/10.1126/science.aax1971

Pierce, M. L., Weston, M. D., Fritzsch, B., Gabel, H. W., Ruvkun, G., \& Soukup, G. A. (2008). MicroRNA-183 family conservation and ciliated neurosensory organ expression. Evolution \& Development, 10(1), 106-113. https://doi.org/10.1111/j.1525-142X.2007.00217.x

Richards, J. L., Zacharias, A. L., Walton, T., Burdick, J. T., \& Murray, J. I. (2013). A quantitative model of normal Caenorhabditis elegans embryogenesis and its 
disruption after stress. Developmental Biology, 374(1), 12-23.

https://doi.org/10.1016/j.ydbio.2012.11.034

Rojo Romanos, T., Pladevall-Morera, D., Langebeck-Jensen, K., Hansen, S., Ng, L., \&

Pocock, R. (2017). LIN-32/Atonal Controls Oxygen Sensing Neuron

Development in Caenorhabditis elegans. Scientific Reports, 7(1), 7294.

https://doi.org/10.1038/s41598-017-07876-4

Santella, A., Du, Z., Nowotschin, S., Hadjantonakis, A.-K., \& Bao, Z. (2010). A hybrid blob-slice model for accurate and efficient detection of fluorescence labeled nuclei in 3D. BMC Bioinformatics, 11, 580. https://doi.org/10.1186/1471-2105$11-580$

Sarafi-Reinach, T. R., \& Sengupta, P. (2000). The forkhead domain gene unc-130 generates chemosensory neuron diversity in C. elegans. Genes \& Development, 14(19), 2472-2485.

Sarov, M., Schneider, S., Pozniakovski, A., Roguev, A., Ernst, S., Zhang, Y., Hyman, A. A., \& Stewart, A. F. (2006). A recombineering pipeline for functional genomics applied to Caenorhabditis elegans. Nature Methods, 3(10), 839-844. https://doi.org/10.1038/nmeth933

Sasai, N., Mizuseki, K., \& Sasai, Y. (2001). Requirement of FoxD3-class signaling for neural crest determination in Xenopus. Development (Cambridge, England), $128(13), 2525-2536$.

Spitzer, S. O., Sitnikov, S., Kamen, Y., Evans, K. A., Kronenberg-Versteeg, D., Dietmann, S., de Faria, O., Agathou, S., \& Káradóttir, R. T. (2019). Oligodendrocyte Progenitor Cells Become Regionally Diverse and Heterogeneous 
with Age. Neuron, 101(3), 459-471.e5.

https://doi.org/10.1016/j.neuron.2018.12.020

Stewart, R. A., Arduini, B. L., Berghmans, S., George, R. E., Kanki, J. P., Henion, P. D., \& Look, A. T. (2006). Zebrafish foxd3 is selectively required for neural crest specification, migration and survival. Developmental Biology, 292(1), 174-188. https://doi.org/10.1016/j.ydbio.2005.12.035

Stout, R. F., \& Parpura, V. (2011). Voltage-gated calcium channel types in cultured C. elegans CEPsh glial cells. Cell Calcium, 50(1), 98-108. https://doi.org/10.1016/j.ceca.2011.05.016

Sulston, J. E., Schierenberg, E., White, J. G., \& Thomson, J. N. (1983). The embryonic cell lineage of the nematode Caenorhabditis elegans. Developmental Biology, $100(1), 64-119$.

Teng, L., Mundell, N. A., Frist, A. Y., Wang, Q., \& Labosky, P. A. (2008). Requirement for Foxd3 in the maintenance of neural crest progenitors. Development (Cambridge, England), 135(9), 1615-1624. https://doi.org/10.1242/dev.012179

Wagner, D. E., Weinreb, C., Collins, Z. M., Briggs, J. A., Megason, S. G., \& Klein, A. M. (2018). Single-cell mapping of gene expression landscapes and lineage in the zebrafish embryo. Science (New York, N.Y.), 360(6392), 981-987. https://doi.org/10.1126/science.aar4362

Wallace, S. W., Singhvi, A., Liang, Y., Lu, Y., \& Shaham, S. (2016). PROS-1/Prospero Is a Major Regulator of the Glia-Specific Secretome Controlling Sensory-Neuron Shape and Function in C. elegans. Cell Reports, 15(3), 550-562. https://doi.org/10.1016/j.celrep.2016.03.051 
Walton, T., Preston, E., Nair, G., Zacharias, A. L., Raj, A., \& Murray, J. I. (2015). The Bicoid class homeodomain factors ceh-36/OTX and unc-30/PITX cooperate in C. elegans embryonic progenitor cells to regulate robust development. PLoS Genetics, 11(3), e1005003. https://doi.org/10.1371/journal.pgen.1005003

Wicks, S. R., Yeh, R. T., Gish, W. R., Waterston, R. H., \& Plasterk, R. H. (2001). Rapid gene mapping in Caenorhabditis elegans using a high density polymorphism map. Nature Genetics, 28(2), 160-164. https://doi.org/10.1038/88878

Yaklichkin, S., Steiner, A. B., Lu, Q., \& Kessler, D. S. (2007). FoxD3 and Grg4 physically interact to repress transcription and induce mesoderm in Xenopus. The Journal of Biological Chemistry, 282(4), 2548-2557.

https://doi.org/10.1074/jbc.M607412200

Yaklichkin, S., Vekker, A., Stayrook, S., Lewis, M., \& Kessler, D. S. (2007). Prevalence of the EH1 Groucho interaction motif in the metazoan Fox family of transcriptional regulators. BMC Genomics, 8, 201. https://doi.org/10.1186/14712164-8-201

Yoshimura, S., Murray, J. I., Lu, Y., Waterston, R. H., \& Shaham, S. (2008). Mls-2 and vab-3 Control glia development, hlh-17/Olig expression and glia-dependent neurite extension in C. elegans. Development (Cambridge, England), 135(13), 2263-2275. https://doi.org/10.1242/dev.019547

Zeisel, A., Hochgerner, H., Lönnerberg, P., Johnsson, A., Memic, F., van der Zwan, J., Häring, M., Braun, E., Borm, L. E., La Manno, G., Codeluppi, S., Furlan, A., Lee, K., Skene, N., Harris, K. D., Hjerling-Leffler, J., Arenas, E., Ernfors, P., Marklund, U., \& Linnarsson, S. (2018). Molecular Architecture of the Mouse 
Nervous System. Cell, 174(4), 999-1014.e22.

https://doi.org/10.1016/j.cell.2018.06.021

Zeisel, A., Muñoz-Manchado, A. B., Codeluppi, S., Lönnerberg, P., La Manno, G., Juréus, A., Marques, S., Munguba, H., He, L., Betsholtz, C., Rolny, C., CasteloBranco, G., Hjerling-Leffler, J., \& Linnarsson, S. (2015). Brain structure. Cell types in the mouse cortex and hippocampus revealed by single-cell RNA-seq. Science (New York, N.Y.), 347(6226), 1138-1142.

https://doi.org/10.1126/science.aaa1934 
Fig. 1
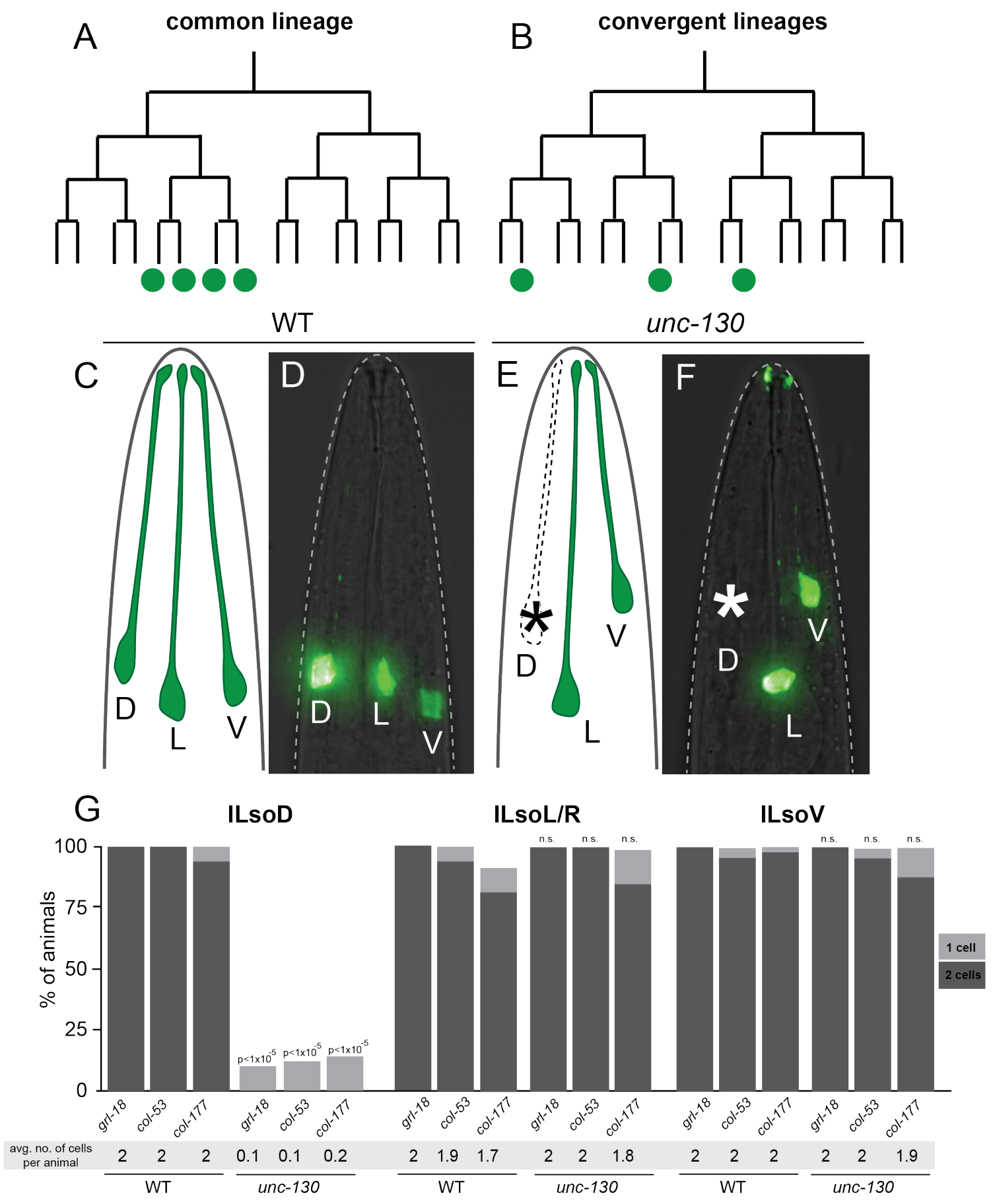


\section{Fig. 1. UNC-130 is required in one of three convergent lineages}

Schematic of a common lineage (A), in which a shared progenitors give rise to a unique cell type and a convergent lineage (B), in which distinct progenitors in divergent lineages produce a unique cell type. Lateral views and schematics of wild-type (C, D) and unc-130 mutant (E, F) animals expressing ILso marker, grl-18pro:YFP. Asterisk denotes missing cells. D - dorsal, L - lateral, V - ventral. (G) Percentage of wild-type and unc-130 mutant animals expressing ILso markers grl-18, col-53, and col-177 in two (dark gray) or one (light gray) dorsal (ILsoD), lateral (ILsoL/R) and ventral (ILsoV) glia. Average number of cells expressing each marker per animal is listed under each condition. $\mathrm{n}=50$ animals per marker and genotype. p-values were calculated by Mann-Whitney test. 
Table 1. Penetrance of phenotypes in Fig. 1

\begin{tabular}{|c|c|c|c|c|c|c|}
\hline & \multicolumn{3}{|c|}{$\%$ of animals with \# of cells } & \multirow[b]{2}{*}{$\mathbf{n}$} \\
\hline cell type & marker & genotype & $\mathbf{0}$ & 1 & 2 & \\
\hline \multirow{2}{*}{ ILsoD } & \multirow{2}{*}{ grl-18 } & wt & 0 & 0 & 100 & 50 \\
\hline & & ev505 & 90 & 10 & 0 & 50 \\
\hline \multirow{2}{*}{ ILsoD } & \multirow{2}{*}{ col-53 } & wt & 0 & 0 & 100 & 50 \\
\hline & & ev505 & 88 & 12 & 0 & 50 \\
\hline \multirow{2}{*}{ ILsoD } & \multirow{2}{*}{ col-177 } & wt & 0 & 6 & 94 & 50 \\
\hline & & ev505 & 86 & 14 & 0 & 50 \\
\hline \multirow{2}{*}{ ILsoL/R } & \multirow{2}{*}{ grl-18 } & wt & 0 & 0 & 100 & 50 \\
\hline & & ev505 & 0 & 0 & 100 & 50 \\
\hline \multirow{2}{*}{ ILsoL/R } & \multirow{2}{*}{ col-53 } & wt & 0 & 6 & 94 & 50 \\
\hline & & ev505 & 0 & 0 & 100 & 50 \\
\hline \multirow{2}{*}{ ILsoL/R } & \multirow{2}{*}{ col-177 } & wt & 8 & 10 & 82 & 50 \\
\hline & & ev505 & 2 & 14 & 84 & 50 \\
\hline \multirow{2}{*}{ ILsoV } & \multirow{2}{*}{ grl-18 } & wt & 0 & 0 & 100 & 50 \\
\hline & & $e v 505$ & 0 & 0 & 100 & 50 \\
\hline \multirow{2}{*}{ ILsoV } & \multirow{2}{*}{ col-53 } & wt & 0 & 4 & 96 & 50 \\
\hline & & ev505 & 0 & 4 & 96 & 50 \\
\hline \multirow{2}{*}{ ILsoV } & \multirow{2}{*}{ col-177 } & wt & 0 & 2 & 98 & 50 \\
\hline & & $e v 505$ & 0 & 12 & 88 & 50 \\
\hline
\end{tabular}


Fig. 2
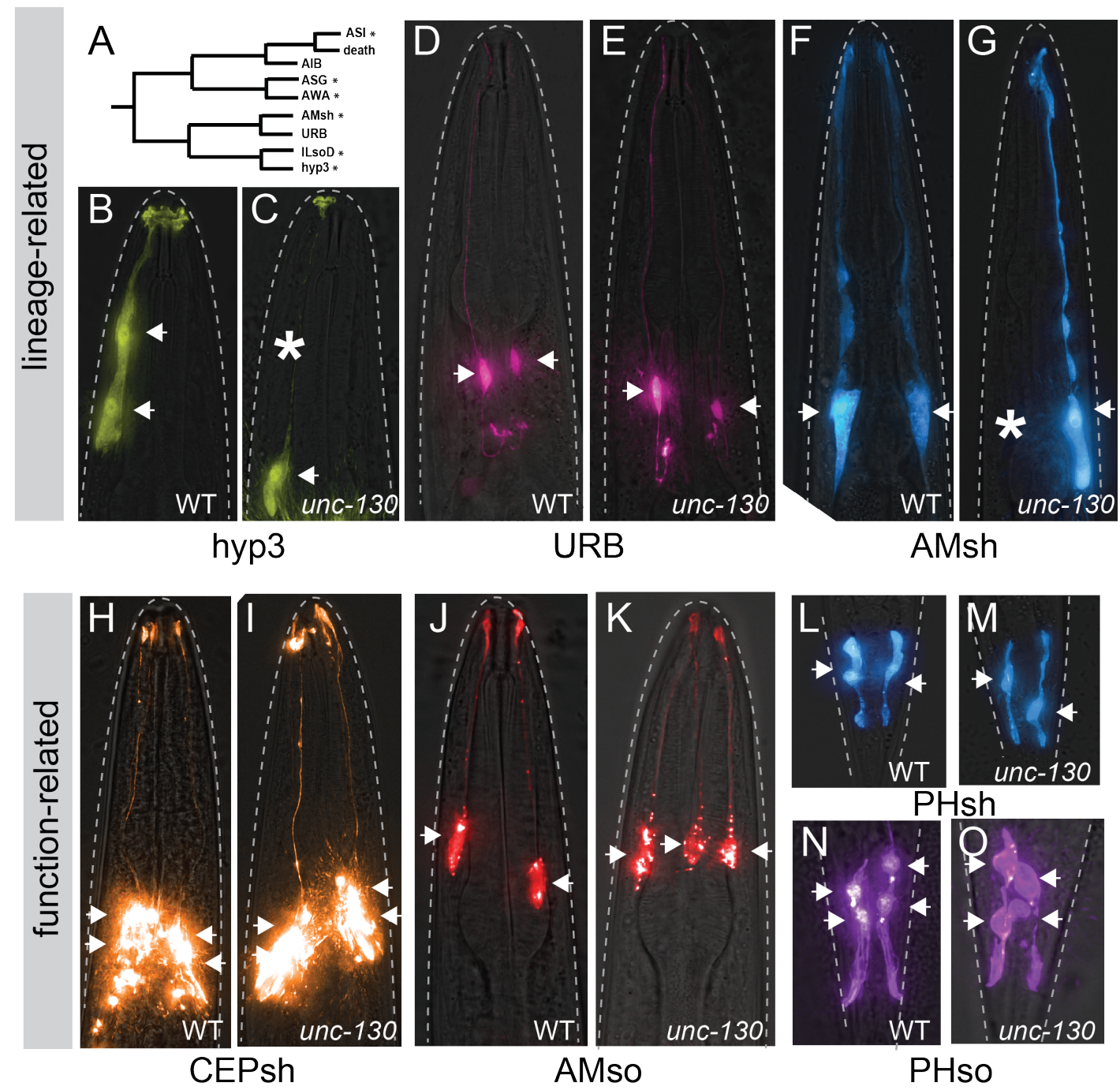

Fig. 2. UNC-130 is required for the specification of lineage-related cell types

(A) Schematic of ILsoD sublineage. Asterisks denote cell types whose specification is affected in unc-130 mutants. Wild-type (B) and unc-130 mutant (C) animals expressing hyp3 marker, ceh-10pro:GFP. Asterisk denotes missing cell. Wild-type (D) and unc-130 mutant (E) animals expressing URB marker, $n l p$-6pro:GFP. Wild-type (F) and unc-130 
mutant (G) animals expressing AMsh marker, F16F9.3pro:mCherry. Asterisk denotes missing cell. Wild-type $(\mathrm{H})$ and $u n c-130$ mutant (I) animals expressing CEPsh marker, hlh-17pro:YFP. Wild-type (J) and unc-130 mutant (K) animals expressing AMso marker, grl-2pro:mCherry. Wild-type (L) and unc-130 mutant (M) animals expressing PHsh marker, F16F9.3pro:mCherry. Wild-type (N) and unc-130 mutant (O) animals expressing PHso marker, grl-2pro:YFP. Arrows denote cell bodies in all images. 
Table 2. Penetrance of phenotypes in Fig. 2.

\begin{tabular}{|c|c|c|c|c|c|c|c|}
\hline \multirow[b]{2}{*}{ cell type } & \multirow[b]{2}{*}{ genotype } & \multicolumn{5}{|c|}{$\%$ of animals with \# of cells } & \multirow[b]{2}{*}{$\mathbf{n}$} \\
\hline & & $\mathbf{0}$ & 1 & 2 & 3 & 4 & \\
\hline \multirow{2}{*}{ hyp3 } & wt & 0 & 0 & 100 & - & - & 50 \\
\hline & ev505 & 6 & 8 & 86 & - & - & 50 \\
\hline \multirow{2}{*}{ URB } & wt & 0 & 2 & 98 & - & - & 50 \\
\hline & ev505 & 0 & 4 & 96 & - & - & 50 \\
\hline \multirow{2}{*}{ AMsh } & wt & 0 & 0 & 100 & - & - & 50 \\
\hline & ev505 & 6 & 32 & 62 & - & - & 53 \\
\hline \multirow{2}{*}{ CEPsh } & wt & 0 & 0 & 0 & 0 & 100 & 50 \\
\hline & ev505 & 0 & 0 & 0 & 6 & 94 & 50 \\
\hline \multirow{2}{*}{ AMso } & wt & 0 & 0 & 100 & 0 & 0 & 50 \\
\hline & ev505 & 0 & 0 & 58 & 34 & 8 & 53 \\
\hline \multirow{2}{*}{ PHsh } & wt & 0 & 12 & 88 & - & - & 50 \\
\hline & ev505 & 0 & 14 & 86 & - & - & 50 \\
\hline \multirow{2}{*}{ PHso } & wt & 0 & 0 & 0 & 4 & 96 & 50 \\
\hline & ev505 & 0 & 0 & 0 & 12 & 88 & 50 \\
\hline
\end{tabular}




\section{Fig. 3}
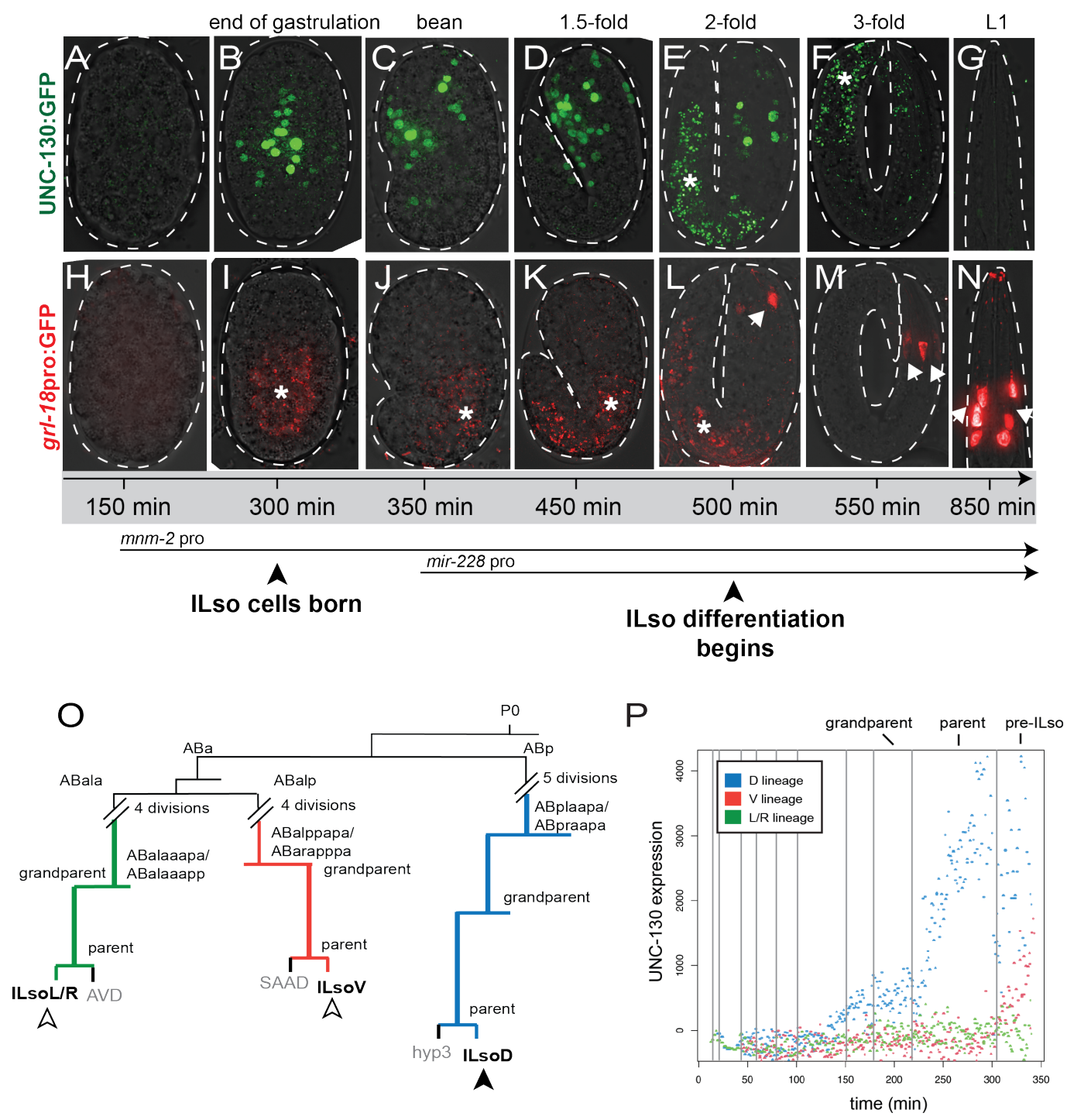

\section{Q}

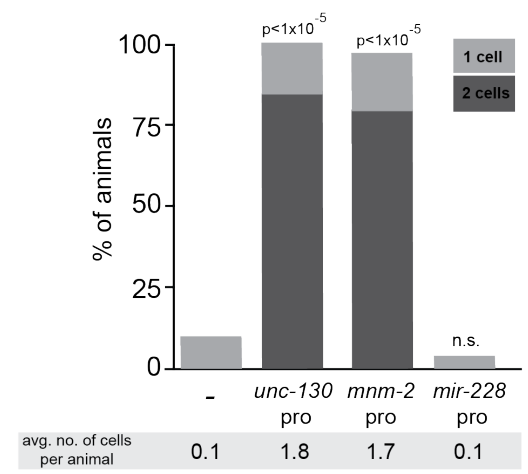

$\mathrm{R}$



avg. no. of cells

$0.1 \quad 0.8$

$0.9 \quad 0.2$

0.1 


\section{Fig. 3. UNC-130 is expressed in a restricted lineage before the onset of differentiation}

(A-G) Time course of embryos expressing UNC-130:GFP. (H-N) Time course of embryos expressing grl-18pro:GFP (pseudo-colored red). Asterisk denotes gut autofluorescence. Arrows denote grl-18+ ILso cells. (O) Lineage diagram of a subset of embryonic cell divisions derived from the AB blastomere that give rise to ILsoD (blue), ILsoV (red), ILsoL/R (green) glia. (P) Levels of UNC-130:GFP signal in ILsoD (blue), ILsoV (red), and ILsoL/R (green) lineages over developmental time. Vertical lines denote cell divisions. (Q) Heterologous promoters were used to drive expression of $u n c-130$ in the $u n c-130$ mutant strain and extent of rescue was assessed. Timing of $m n m$-2pro and mir-228pro expression is marked in (A). Percentage of animals expressing grl-18pro:YFP in one or two ILsoD glia in each condition. Average number of cells marked per animal is listed under each condition. $\mathrm{n}=50$ animals per condition. $\mathrm{p}$-values were calculated by Mann-Whitney test. (R) unc-130 mutant embryos expressing hsp:unc-130 were heatshocked at different time points and extent of rescue was assessed. Percentage of animals expressing grl-18pro:YFP in one or two ILsoD glia in each condition. Average number of cells marked per animal is listed under each condition. $n=50$ animals per condition. p-values were calculated by Mann-Whitney test. 
Fig. 4



Fig. 4. UNC-130 acts as a repressor to specify glial fates

(A) Schematic diagram of UNC-130 constructs used in rescue experiments to determine domain function. (B) unc-130 promoter was used to drive expression of individual constructs in the unc-130 mutant strain and extent of rescue was assessed. Percentage of 
animals expressing grl-18pro:YFP in one or two ILsoD glia in each condition. Average

number of cells marked per animal is listed under each condition. $\mathrm{n}=50$ animals per

condition. p-values were calculated by Mann-Whitney test. 
Fig. 5

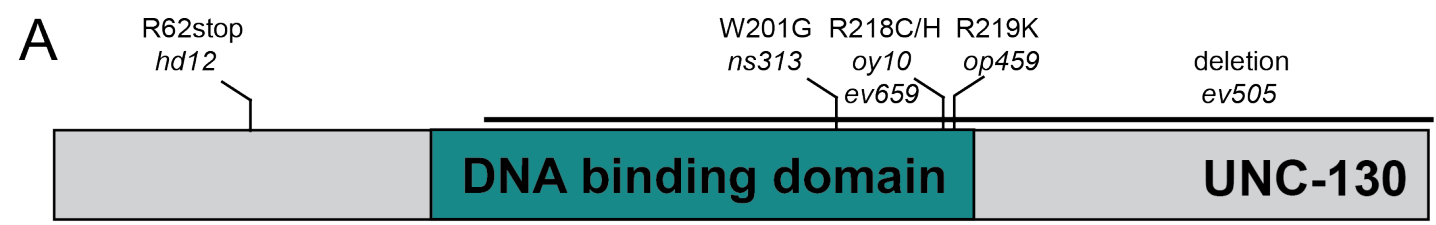

UNC-130 . . PGNPGKGNYWALDPNCEDMFDNGSFLRRRKRYKKN . . . FoxD3 ...PGNPGKGNYWTLDPQSEDMFDNGSFLRRRKRFKRH. .

B

\section{Known motifs UNC-130 motifs}

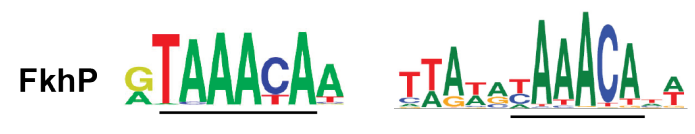

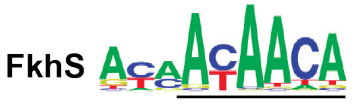

D

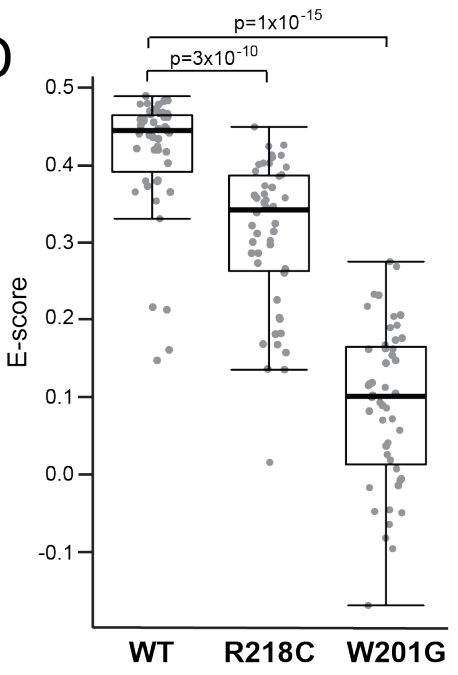

C



E

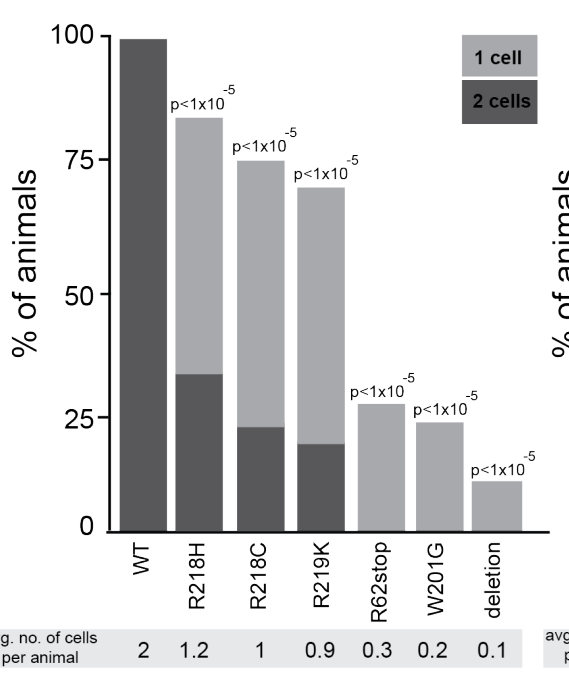

F

F

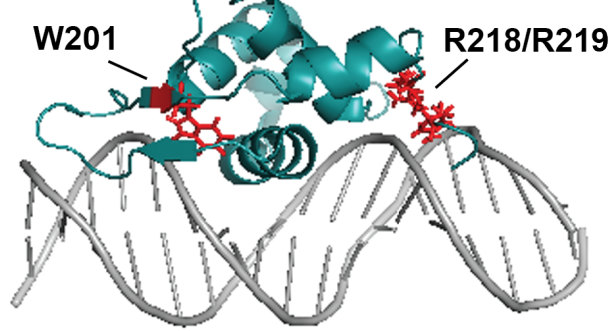




\section{Fig. 5. Severity of glial phenotypes correlate with UNC-130:DNA binding defects}

(A) Schematic diagram of UNC-130 protein with DNA-binding domain (turquoise)

highlighted. Location of point mutations and deletion are indicated. Alignment of UNC-

130 and FoxD3 DBD with point mutations highlighted in red. (B) Logos of vertebrate

primary (FkhP, top) and secondary (FkhS, bottom) Forkhead motifs (Nakagawa et al.,

2013) and UNC-130 preferred DNA sequences that resemble primary (top) and

secondary (bottom) motifs as determined by this study. Core motifs are underlined. (C)

Structure of FoxD3 DBD (turquoise) interacting with DNA (gray) (Protein Data Bank ID

code 2HDC, (Jin et al., 1999)). W201, R218, and R219 residues are highlighted in red.

(D) Scatter plot of E-scores for 8-mer DNA sequences matching [A/G][C/T]AAACA or

$\mathrm{AA}[\mathrm{C} / \mathrm{T}] \mathrm{AACA}$ from protein binding microarray assays of wild-type, $\mathrm{R} 218 \mathrm{C}$, and

W201G mutant UNC-130 proteins. Black lines represent population median; top and

bottom of boxes are $25^{\text {th }}$ and $75^{\text {th }}$ percentiles, respectively; and top and bottom of

whiskers are either most extreme point or $1.5 \mathrm{x}$ the interquartile range. $\mathrm{p}$-values were

calculated by Mann-Whitney test. (E) Percentage of animals expressing grl-18pro:YFP in

one or two ILsoD glia in wild-type and unc-130 mutant strains. Average number of cells

marked per animal is listed under each condition. $\mathrm{n}=50$ animals per genotype. $\mathrm{p}$-values

were calculated by Mann-Whitney test. (F) unc-130 promoter was used to drive

expression of unc-130 and human FOXD3 separately in the $u n c-130$ mutant strain and

extent of rescue was assessed. Percentage of animals expressing grl-18pro:YFP in one or

two ILsoD glia in each condition. Average number of cells marked per animal is listed 
bioRxiv preprint doi: https://doi.org/10.1101/758508; this version posted December 14,2020 . The copyright holder for this preprint (which was not certified by peer review) is the author/funder, who has granted bioRxiv a license to display the preprint in perpetuity. It is made available under aCC-BY-NC-ND 4.0 International license.

under each condition. $\mathrm{n}=50$ animals per condition. $\mathrm{p}$-values were calculated by Mann-

Whitney test. 


\section{Supplemental Material}

Fig. S1

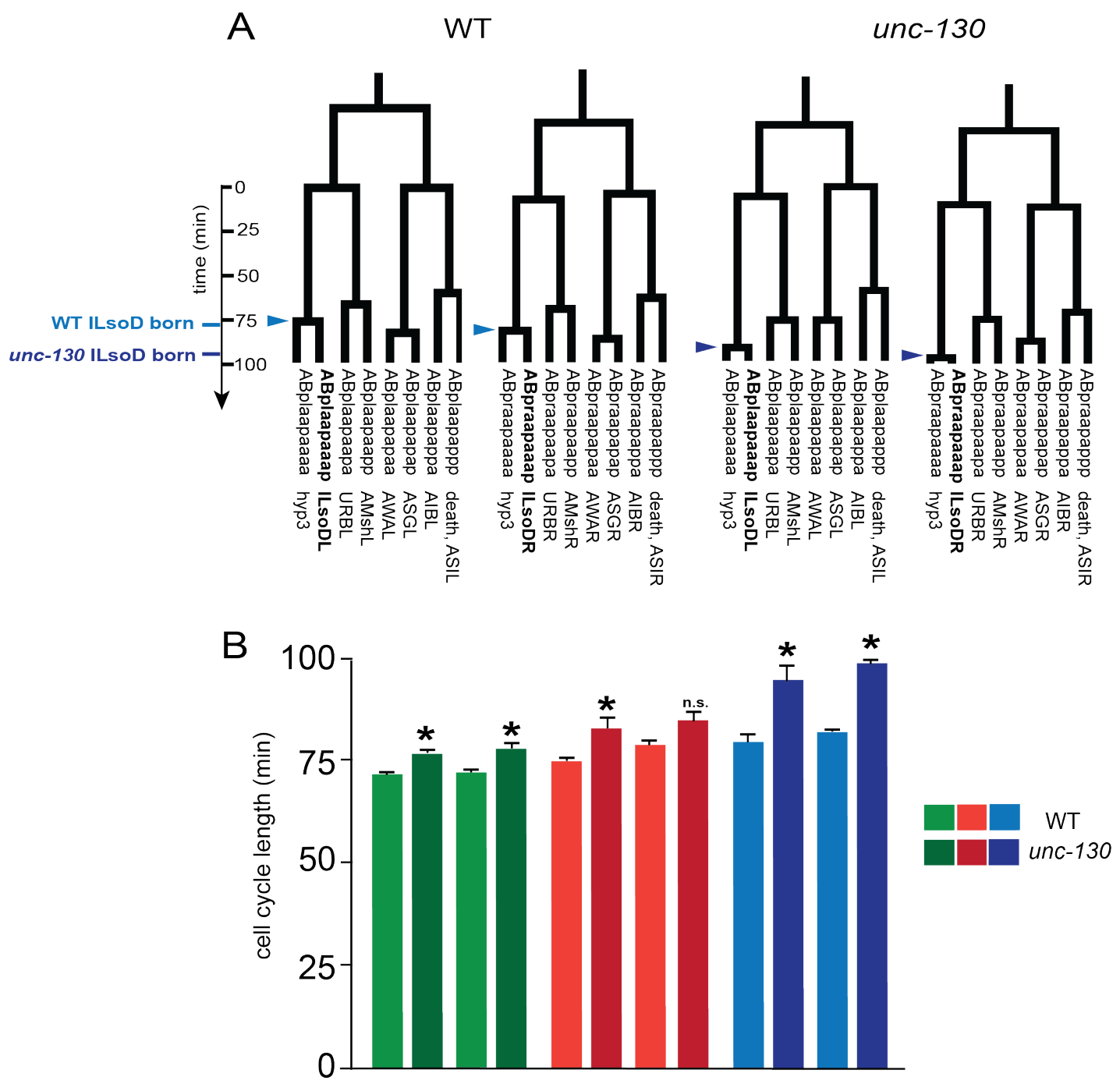

progenitor of: ILsoL ILsoR ILsoVL ILsoVR ILsoDL ILsoDR 


\section{Fig S1. Related to Fig. 1}

(A) Two example ILsoD (ABpxaapaa) lineages from wild-type and unc-130 mutant embryos. Light blue arrowheads denote division of wild-type ILsoD progenitors and dark blue arrowheads denote divisions of $u n c-130$ mutant ILsoD progenitors that produce ILsoD and hyp3 cells. (B) Cell cycle lengths of ILsoL, ILsoR, ILsoVL, ILsoVR, ILsoDL, and ILsoDR progenitor cells in wild-type and unc-130 mutant embryos. $\mathrm{n}=6$ for wild type, $\mathrm{n}=8$ for $u n c-130$ mutants. Error bars - SE. Asterisks denote $\mathrm{p}$-value $<0.05$ as calculated by Welch's t-test. 
Fig. S2.
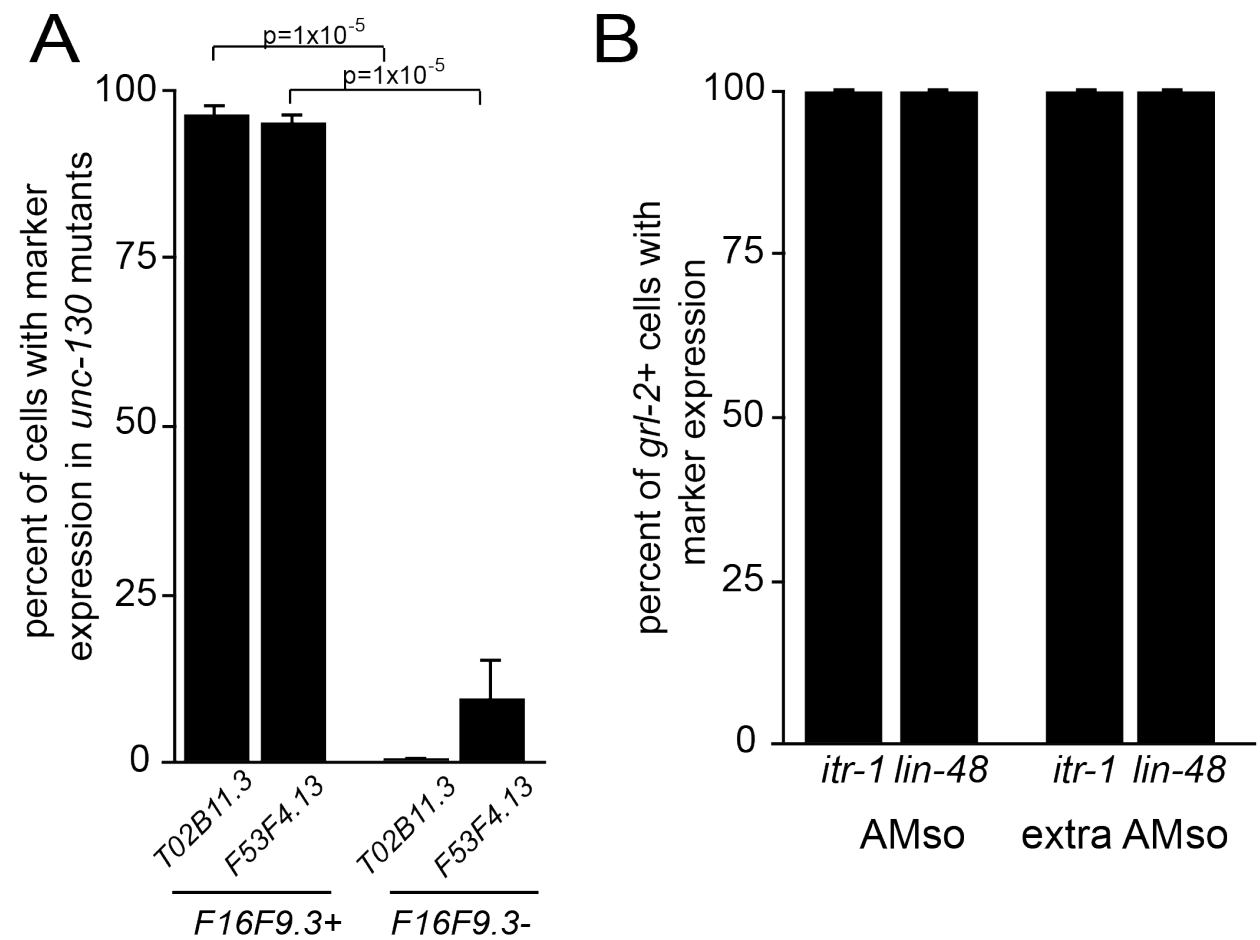

\section{AMso}
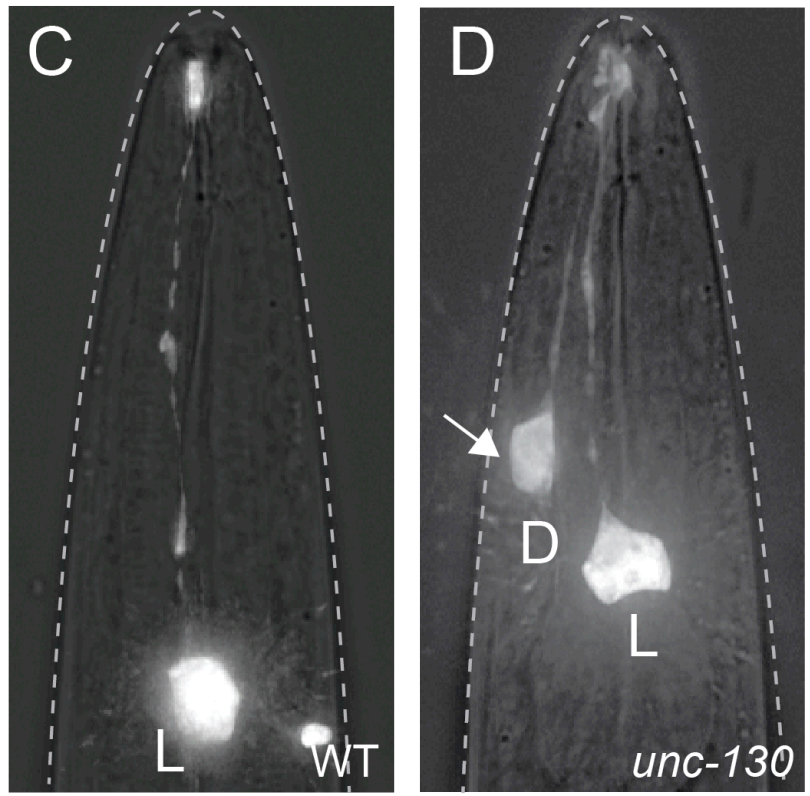


\section{Fig. S2. Related to Fig. 2}

(A) Percentage of F16F9.3+ and F16F9.3- cells co-expressing AM sheath markers, T02B11.3pro:GFP and F53F4.13pro:GFP, in $u n c-130$ mutant animals. $\mathrm{n} \geq 20$ cells. Error bars - standard error of proportion. p-values calculated by z-score for two population proportions. (B) Percentage of grl-2+ cells co-expressing AMso markers, lin-48p:GFP and itr-1p:GFP, in endogenous and extra cells in unc-130 mutants. Error bars - standard error of proportion. Lateral views of wild-type (C) and unc-130 mutant (D) animals expressing AMso marker, grl-2pro:YFP. Arrow indicates extra cell. D - dorsal, L lateral. 


\section{Fig. S3}


$150 \mathrm{~min}$

$300 \mathrm{~min}$

$350 \mathrm{~min}$

$450 \mathrm{~min}$

$500 \mathrm{~min}$

\section{Fig. S3. Related to Fig. 3}

Time course of mnm-2pro:GFP (A-E) and mir-228pro:GFP (F-J) expression in embryos. 
Fig. S4

A

GAL4 DBD

\begin{tabular}{|l|l|l|}
\hline UNC-130 N-term & GAL4 DBD & UNC-130 C-term \\
\hline
\end{tabular}

\begin{tabular}{|l|l|} 
GAL4 DBD & UNC-130 C-term
\end{tabular}

\begin{tabular}{|c|c|c|}
\hline $5 X$ UAS & SV40 pro & firefly luciferase \\
\hline
\end{tabular}

$\mathrm{B}$

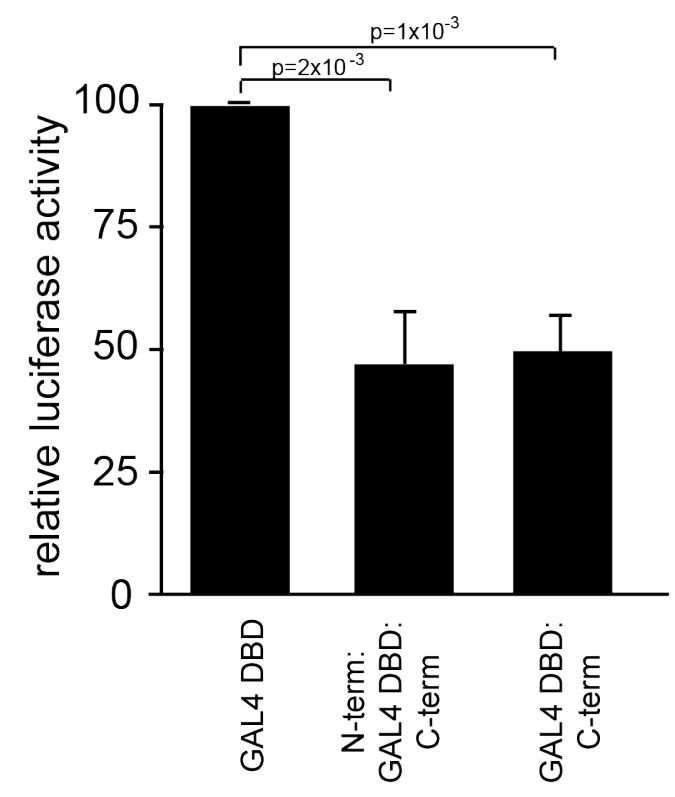

Fig S4. Related to Fig. 4

(A) Schematic diagram of constructs used in luciferase assays. (B) GAL4DBD alone, Nterm:GAL4DBD:C-term, or GAL4DBD:C-term, along with a UAS-firefly luciferase reporter and constitutively expressed renilla luciferase were transfected into HEK293T cells. Relative firefly luciferase activity, first normalized to renilla luciferase 
bioRxiv preprint doi: https://doi.org/10.1101/758508; this version posted December 14,2020 . The copyright holder for this preprint (which was not certified by peer review) is the author/funder, who has granted bioRxiv a license to display the preprint in perpetuity. It is made available under aCC-BY-NC-ND 4.0 International license.

bioluminescence in each sample, and then to DBD-GAL4 alone. Error bars - SD; pvalues calculated by Welch's t-test. 
Fig. S5

\author{
A \\ UNC-130 \\ -MLFSMESILSSTKPKLEPPPKLEP--EVTINEQVVDLPR--SNTRLSEPST \\ FoxD3 MTLSGGGSASDMSGQTVLTAEDVDIDVVGEGDDGLEEKDSDAGCDSPAGPPELRLDEADE \\ SASVLEHDLKFGESRKRSRSLGDEPTEDEDGVPVRKANKRNHSTSSAADSSSDDAKDDDD \\ VPPAAPHHGQPQPPHQQPLTLPKEAAGAGAGPGGDVGAPEADGCKGGVGGEEGGASGGGP
}

DDDSTSRKSMSGHR-KSSHAKPPYSYIALIAMSILNSPEKKLTLSEICEFIINKFEYYKE GAGSGSAGGLAPSKPKNSLVKPPYSYIALITMAILQSPQKKLTLSGICEFISNRFPYYRE

KFPAWQNSIRHNLSLNDCFVKVARGPGNPGKGNYWALDPNCEDMFDNGSFLRRRKRYKKN KFPAWQNSIRHNLSLNDCFVKIPREPGNPGKGNYW̄TLDPQSEDMFDNGSFLRRRKRFKRH $* * * * * * * * * * * * * * * * * * * * *$ $* * * * * * * * * \bar{*} * * * \quad * * * * * * * * * * * * * * * \quad *$

SDTYH------EMMSHHPMPFPPFLPQGMPFP-PRMMHPMANIPMLGHPMNPRAVPNMPA QQEHLREQTALMMQSFGAYSLAAAAGAAGPYGRPYGLHPAAAAFAYSHPAAAAAAAAAAA

FFIPQNID-n-n LQYPYALPPVAPVLPPAVPLLPSGELGRKAAAFGSQLGPGLQLGLNSLGAAAAAAGTAGA

SGQKRTSSSSSSPNENGSSAVSDKLSA

AGTTASLIKSEPSARPSFSINIIGGGPAAPGGSAVGAGVAGGTGGSGGGSTAQSFLRPP

GTVQSAALMATHQPLSLSRTTATIAPILSVPLSGQFLQPAASAAAAAAAAAQAKWPAQ



\section{Fig. S5. Related to Fig. 5}

(A) Alignment of UNC-130 (black) and FoxD3 (gray) sequences. DNA binding domain is highlighted in green. Eh1 motifs are highlighted in blue. Asterisks denote conserved amino acids in the DNA binding domain. Underlined residues are mutated in point mutants described in Fig. 5. (B) Technical replicate of PBM experiment from Fig. 5D. Scatter plot of E-scores for 8-mer DNA sequences matching $[\mathrm{A} / \mathrm{G}][\mathrm{C} / \mathrm{T}] \mathrm{AAACA}$ or $\mathrm{AA}[\mathrm{C} / \mathrm{T}] \mathrm{AACA}$ from protein binding microarray (PBM) assays of wild-type, $\mathrm{R} 218 \mathrm{C}$, and W201G mutant proteins. Black lines represent population median, top and bottom of boxes are $25^{\text {th }}$ and $75^{\text {th }}$ percentiles, respectively, and top and bottom of whiskers are either most extreme point or $1.5 \mathrm{x}$ the interquartile range. $\mathrm{p}$-values calculated by MannWhitney test. (C) Scatter plot of E-scores for 8-mer DNA sequences matching $[\mathrm{A} / \mathrm{G}][\mathrm{C} / \mathrm{T}] \mathrm{AAACA}$ or AA[C/T]AACA for wild-type versus $\mathrm{R} 218 \mathrm{C}$ mutant proteins. Linear regression, $\mathrm{R}^{2}=0.72$ 
Table S1. Strains generated for this study

\begin{tabular}{|c|c|c|}
\hline ID & Genotype & Figures \\
\hline CHB3747 & $h m n E x 2123$ [grl-2pro:CFP + grl-18pro:YFP] & 1 \\
\hline CHB3756 & unc-130 (ev505); hmnEx2126 [grl-2pro:CFP + grl-18pro:YFP] & 1 \\
\hline CHB3310 & hmnIs 47 [grl-18pro:mApple]; ynIs 78 [flp-8pro:GFP] & 1,5 \\
\hline CHB3311 & $\begin{array}{l}\text { unc-130 (ev505); hmnIs } 47 \text { [grl-18pro:mApple]; ynIs } 78 \text { [flp- } \\
\text { 8pro:GFP] }\end{array}$ & 1 \\
\hline CHB4124 & $\begin{array}{l}\text { hmnIs } 47 \text { [grl-18pro:mApple]; hmnEx2227 [col-53pro:GFP + } \\
\text { pRF4] }\end{array}$ & 1 \\
\hline CHB4143 & $\begin{array}{l}\text { unc-130 (ev505); hmnIs47 [grl-18pro:mApple]; hmnEx2227 [col- } \\
\text { 53pro:GFP + pRF4] }\end{array}$ & 1 \\
\hline CHB4064 & $\begin{array}{l}\text { hmnIs } 47 \text { [grl-18pro:mApple]; hmnEx2171 [col-177pro:GFP + } \\
\text { pRF4] }\end{array}$ & 1 \\
\hline CHB4125 & $\begin{array}{l}\text { unc-130 (ev505); hmnIs47 [grl-18pro:mApple]; hmnEx2171 [col- } \\
\text { 177pro:GFP + pRF4] }\end{array}$ & 1 \\
\hline CHB3933 & ujIs 113; wgIs476 & $\mathrm{S} 1$ \\
\hline CHB4067 & ev505 ujIs 113; wgIs476 & $\mathrm{S} 1$ \\
\hline CHB4046 & hmnIs 100 [ceh-10pro:GFP + pRF4] & 2 \\
\hline CHB4047 & unc-130 (ev505); hmnIs 100 [ceh-10pro:GFP + pRF4] & 2 \\
\hline CHB4066 & hmnEx2237 [nlp-6pro:GFP + pRF4] & 2 \\
\hline CHB4163 & unc-130 (ev505); hmnEx2237 [nlp-6pro:GFP + pRF4] & 2 \\
\hline CHB3463 & unc-130 (ev505); irIs67 [hlh-17pro:GFP]; unc-119 & 2 \\
\hline CHB1634 & $\begin{array}{l}\text { unc-130 (ev505); hmnIs } 13 \text { [F16F9.3pro:mCherry + grl-2pro:YFP } \\
+ \text { gcy-8pro:CFP] }\end{array}$ & 2 \\
\hline CHB1549 & hmnIs 13 [F16F9.3pro:mCherry + grl-2pro:YFP + gcy-8pro:CFP] & 2 \\
\hline CHB3850 & hmnEx1910 [grl-2pro:mCherry + itr-1pro:YFP + pRF4] & $\mathrm{S} 2$ \\
\hline CHB3355 & $\begin{array}{l}\text { unc-130 (ev505); hmnEx1910 [grl-2pro:mCherry + itr-1pro:YFP + } \\
\text { pRF4] }\end{array}$ & $\mathrm{S} 2$ \\
\hline CHB3422 & saIs14 [lin-48pro:GFP]; hmnEx1939 [grl-2pro:mCherry + pRF4] & $\mathrm{S} 2$ \\
\hline CHB3441 & unc-130 (ev505); sals14 [lin-48pro:GFP]; hmnEx1951 [grl- & $\mathrm{S} 2$ \\
\hline
\end{tabular}




\begin{tabular}{|c|c|c|}
\hline & 2pro:mCherry; pRF4] & \\
\hline CHB3221 & $\begin{array}{l}\text { hmnEx1715 [F53F4.13pro:GFP + pRF4]; hmnIs } 13 \\
{[\text { [F16F9.3pro:mCherry + grl-2pro:YFP + gcy-8pro:CFP }]}\end{array}$ & $\mathrm{S} 2$ \\
\hline CHB2966 & $\begin{array}{l}\text { hmnEx1683 [T02B11.3pro:GFP + pRF4]; hmnIs } 13 \\
{[\text { [F16F9.3pro:mCherry + grl-2pro:YFP + gcy-8pro:CFP }]}\end{array}$ & $\mathrm{S} 2$ \\
\hline CHB3045 & $\begin{array}{l}\text { unc-130 (ev505); hmnEx1715 [F53F4.13pro:GFP + pRF4]; } \\
\text { hmnIs } 13 \text { [F16F9.3pro:mCherry + grl-2pro:YFP + gcy-8pro:CFP] }\end{array}$ & $\mathrm{S} 2$ \\
\hline CHB3030 & $\begin{array}{l}\text { unc-130 (ev505); hmnEx1683 [T02B11.3pro:GFP + pRF4]; } \\
\text { hmnIs } 13 \text { [F16F9.3pro:mCherry + grl-2pro:YFP + gcy-8pro:CFP] }\end{array}$ & $\mathrm{S} 2$ \\
\hline CHB3775 & hmnIs 82 [grl-18pro:GFP] & 3 \\
\hline CHB4160 & unc-130 (ev505); hmnIs82 [grl-18pro:GFP] & 3 \\
\hline CHB3313 & $\begin{array}{l}\text { unc-130 (ev505); hmnEx1903 [unc-130pro4:unc-130 + grl- } \\
\text { 18pro:GFP + flp-8pro:mCherry + pRF4] }\end{array}$ & $3,4,5$ \\
\hline CHB4174 & $\begin{array}{l}\text { unc-130 (ev505); hmnIs } 82 ; \text { hmnEx2273 [mnm-2pro:unc-130 + } \\
\text { pRF4] }\end{array}$ & 3 \\
\hline CHB4157 & $\begin{array}{l}\text { unc-130 (ev505); hmnIs82; hmnEx2282 [mir-228pro:unc-130+ } \\
\text { grl-18pro:YFP + pRF4] }\end{array}$ & 3 \\
\hline CHB4158 & $\begin{array}{l}\text { unc-130 (ev505); hmnEx2283 [hsp16-2pro:unc-130 + hspl6- } \\
\text { 41pro:unc-130 + grl-18p:YFP + unc-122pro:RFP) }\end{array}$ & 3 \\
\hline CHB1996 & hmnEx1138 [mnm-2pro:GFP + egl-38pro:nls-mCherry + pRF4] & S3 \\
\hline CHB3447 & $\begin{array}{l}\text { unc-130 (ev505); hmnEx1964 [unc-130pro4:DBD + grl-18pro:GFP } \\
+ \text { flp-8:mCherry + pRF4] }\end{array}$ & 4 \\
\hline CHB3428 & $\begin{array}{l}\text { unc-130 (ev505); hmnEx1945 [unc-130pro4:DBD-VP64 + grl- } \\
\text { 18pro:GFP + flp-8:mCherry + pRF4] }\end{array}$ & 4 \\
\hline CHB3381 & $\begin{array}{l}\text { unc-130 (ev505); hmnEx1922 [unc-130pro4:N-TERM + grl- } \\
\text { 18pro:GFP + flp-8:mCherry + pRF4] }\end{array}$ & 4 \\
\hline CHB3402 & $\begin{array}{l}\text { unc-130 (ev505); hmnEx1927 [unc-130pro4: del eh1 N-TERM + } \\
\text { grl-18pro:GFP + flp-8:mCherry + pRF4] }\end{array}$ & 4 \\
\hline CHB3427 & $\begin{array}{l}\text { unc-130 (ev505); hmnEx1944 [unc-130pro4:C-TERM + grl- } \\
\text { 18pro:GFP + flp-8:mCherry + pRF4] }\end{array}$ & 4 \\
\hline CHB4144 & $\begin{array}{l}\text { unc-130 (ev505); hmnEx2275 [unc-130pro4:DBD-Engrailed + grl- } \\
\text { 18pro:GFP + pRF4] }\end{array}$ & 4 \\
\hline CHB4139 & $\begin{array}{l}\text { unc-130 (ev505); hmnEx2274 [unc-130pro4: del eh1 unc-130+ } \\
\text { grl-18pro:YFP + F16F9.3pro:CFP + pRF4) }\end{array}$ & 4 \\
\hline
\end{tabular}




\begin{tabular}{|l|l|l|}
\hline CHB3381 & $\begin{array}{l}\text { unc-130 (hd12); hmnIs47 [grl-18pro:mApple]; ynIs48 [flp- } \\
\text { 8pro:GFP] }\end{array}$ & 5 \\
\hline CHB3382 & $\begin{array}{l}\text { unc-130 (ns313); hmnIs47 [grl-18pro:mApple]; ynIs48 [flp- } \\
\text { 8pro:GFP] }\end{array}$ & 5 \\
\hline CHB3384 & $\begin{array}{l}\text { unc-130 (oy10); hmnIs47 [grl-18pro:mApple]; ynIs48 [flp- } \\
\text { 8pro:GFP] }\end{array}$ & 5 \\
\hline CHB3382 & $\begin{array}{l}\text { unc-130 (ev659); hmnIs47 [grl-18pro:mApple]; ynIs48 [flp- } \\
\text { 8pro:GFP] }\end{array}$ & 5 \\
\hline CHB3378 & $\begin{array}{l}\text { unc-130 (op459); hmnIs47 [grl-18pro:mApple]; ynIs48 [flp- } \\
\text { 8pro:GFP] }\end{array}$ & 5 \\
\hline CHB3411 & $\begin{array}{l}\text { unc-130 (ev505); hmnEx1936 [unc-130pro4:FOXD3, grl- } \\
\text { 18pro:GFP, flp-8:mCherry, pRF4] }\end{array}$ & 5 \\
\hline
\end{tabular}

\section{Strains generated in previous studies}

\begin{tabular}{|l|l|l|l|}
\hline ID & Genotype & Fig. & Source/Reference \\
\hline CHB3906 & OP476 wgIs476 [unc-86::TY1::EGFP::3xFLAG] & S1 & (Sarov et al., 2006) \\
\hline CHB3463 & irIs67 [hlh-17pro:GFP]; unc-119 & 2 & $\begin{array}{l}\text { (Stout \& Parpura, } \\
2011)\end{array}$ \\
\hline CHB1365 & saIs14 [lin-48pro:GFP] & S2 & (Johnson et al., 2001) \\
\hline CHB2348 & OP77 wgIs77 [unc-130::TY1::EGFP::3xFLAG] & 3 & (Sarov et al., 2006) \\
\hline CHB3940 & $\begin{array}{l}\text { RW11144 itIs37 [pie-1pro:mCherry], stIs 10116 } \\
{[\text { his-72pro:his-24:mCherry]; wgIs76 [unc- }} \\
\text { 130:TY1:EGFP:3xFLAG] }\end{array}$ & 3 & (Murray et al., 2012) \\
\hline CHB3840 & nsIs198 [mir-228pro:GFP] & S3 & (Pierce et al., 2008) \\
\hline
\end{tabular}

Table S2. Plasmids generated for this study

\begin{tabular}{|l|l|}
\hline ID & Name \\
\hline pKM47 & grl-18pro:YFP \\
\hline pKM15 & grl-2pro:YFP \\
\hline pKM117 & grl-2pro:CFP \\
\hline
\end{tabular}




\begin{tabular}{|c|c|}
\hline pIL36 & grl-2pro:mCherry \\
\hline pKM16 & F16F9.3pro:CFP \\
\hline pKM55 & pDest15 UNC-130 DBD \\
\hline pKM69 & pDest15 R218C UNC-130 DBD \\
\hline pKM71 & pDest15 W201G UNC-130 DBD \\
\hline pKM59 & unc-130pro4:UNC-130 \\
\hline pKM77 & unc-130pro4:N-term:UNC-130 DBD \\
\hline pKM79 & unc-130pro4:UNC-130 DBD:C-term \\
\hline pKM88 & $\begin{array}{l}\text { unc-130pro4:del eh1 N-term:UNC-130 } \\
\text { DBD }\end{array}$ \\
\hline pKM78 & unc-130pro4:UNC-130 DBD \\
\hline pKM83 & unc-130pro4:UNC-130 DBD VP64 \\
\hline pKM80 & unc-130pro4: del eh1 UNC-130 \\
\hline pKM115 & 5XUAS SV40pro:firefly luciferase \\
\hline pKM114 & CAGpro: renilla luciferase \\
\hline pKM111 & CAGpro:GAL4DBD:UNC-130 C-term \\
\hline pKM113 & CAGpro:GAL4DBD \\
\hline pKM108 & $\begin{array}{l}\text { CAGpro:UNC-130 N-term:GAL4DBD:UNC-130 } \\
\text { C-term }\end{array}$ \\
\hline pKM72 & unc-130pro4:FOXD3 \\
\hline pKM119 & mir-228pro:unc-130 \\
\hline pKM118 & $m n m-2$ pro:unc-130 \\
\hline pKM67 & hsp16-2pro:unc-130 \\
\hline pKM68 & hsp16-41pro:unc-130 \\
\hline
\end{tabular}

Table S3 — Primers of general interest 
bioRxiv preprint doi: https://doi.org/10.1101/758508; this version posted December 14,2020 . The copyright holder for this preprint (which was not certified by peer review) is the author/funder, who has granted bioRxiv a license to display the preprint in perpetuity. It is made available under aCC-BY-NC-ND 4.0 International license.

\begin{tabular}{|l|l|}
\hline Name & Sequence \\
\hline unc-130pro4_fwd & gtactCCTGCAGGctttcaattgaaaattccgaga \\
\hline unc-130pro4_rev & gatcGGCGCGCCtgttACCGGTgtctacctagt \\
\hline
\end{tabular}

